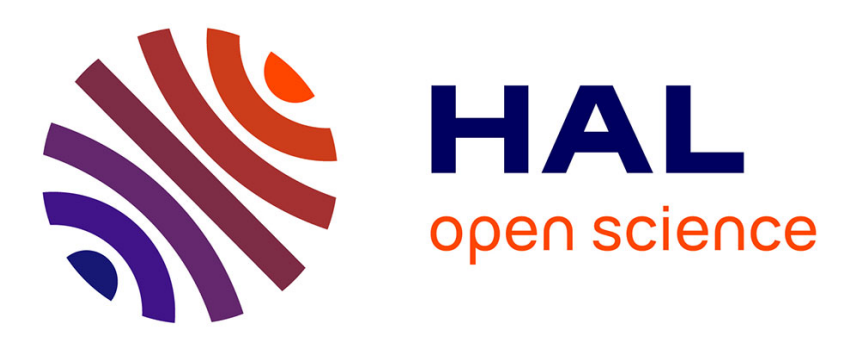

\title{
Locating surface deformation induced by earthquakes using GPS, GLONASS and Galileo ionospheric sounding from a single station
}

Florian Zedek, Lucie Rolland, T. Dylan Mikesell, Anthony Sladen, Bertrand Delouis, Cédric Twardzik, Pierdavide Coïsson

\section{To cite this version:}

Florian Zedek, Lucie Rolland, T. Dylan Mikesell, Anthony Sladen, Bertrand Delouis, et al.. Locating surface deformation induced by earthquakes using GPS, GLONASS and Galileo ionospheric sounding from a single station. Advances in Space Research, 2021, 68 (8), pp.3403-3416. 10.1016/j.asr.2021.06.011 . hal-03452276

\section{HAL Id: hal-03452276 https://hal.science/hal-03452276}

Submitted on 2 Dec 2021

HAL is a multi-disciplinary open access archive for the deposit and dissemination of scientific research documents, whether they are published or not. The documents may come from teaching and research institutions in France or abroad, or from public or private research centers.
L'archive ouverte pluridisciplinaire $\mathbf{H A L}$, est destinée au dépôt et à la diffusion de documents scientifiques de niveau recherche, publiés ou non, émanant des établissements d'enseignement et de recherche français ou étrangers, des laboratoires publics ou privés. 


\section{Locating surface deformation induced by earthquakes using GPS, GLONASS and Galileo ionospheric sounding from a single station}

Florian Zedek ${ }^{1}$, Lucie M. Rolland ${ }^{1 *}$, T. Dylan Mikesell², Anthony Sladen ${ }^{1}$, Bertrand Delouis ${ }^{1}$, Cédric Twardzik ${ }^{1,4}$, Pierdavide Coïsson ${ }^{3}$

1- Université Côte d'Azur, IRD, CNRS, Observatoire de la Côte d'Azur, Geoazur, Valbonne, France (*Irolland@geoazur.unice.fr)

2- Environmental Seismology Laboratory, Department of Geosciences, Boise State University, Boise Idaho, USA

3- Université de Paris, Institut de physique du globe de Paris, CNRS, F-75005 Paris, France

4- Now at Institut de physique du globe de Strasbourg, Strasbourg, France

\section{E-mail addresses:}

Florian Zedek: zedek@geoazur.unice.fr; Lucie M. Rolland: Irolland@geoazur.unice.fr; T. Dylan Mikesell: DylanMikesell@boisestate.edu; Anthony Sladen: sladen@geoazur.unice.fr; Bertrand Delouis:

delouis@geoazur.unice.fr; Cédric Twardzik: twardzik@unistra.fr; Pierdavide Coïsson: coisson@ipgp.fr

\section{Abstract}

Monitoring earthquakes to rapidly forecast their consequences remains a challenging task, especially in areas far from seismic and geodetic networks. Large and shallow earthquakes induce disturbances in the ionospheric Total Electron Content (TEC). These disturbances are commonly detected using Global Navigation Satellite Systems (GNSS) stations that can sound the ionosphere at great distances. To address this instrumentation sparsity issue, we assess a single GNSS station's ability to constrain the origin location of a coseismic ionospheric disturbance (CID) using observations of TEC. We develop a grid-search method that explores different trial origins (i.e. source locations) to determine which synthetic CID signal best matches the observed TEC time series.

We confirm that a larger number of monitoring satellites enhances the opportunity to have the favorable geometrical coverage of satellites needed to resolve CID origins. We use TEC data acquired during two earthquakes having different moment magnitudes: a Mw 7.1 from Turkey and a Mw 7.8 from New Zealand. Using a well-placed multi-GNSS station we are able to retrieve the CID origin with an accuracy of $50 \mathrm{~km}$ and a theoretical precision of the same order. We conclude that the possibility for a very sparse network of multi-GNSS stations to provide an independent estimate of the spatial distribution of large scale coseismic motions is possible, including offshore areas 200 to $300 \mathrm{~km}$ from the coastline. 


\section{1- Introduction:}

Worldwide, earthquakes are routinely monitored to rapidly forecast their consequences.

Earthquake early-warnings systems are fed by ground motion measurements recorded by seismological and geodetic networks. Focusing on tsunami early-warning systems, the critical forecast model input is the distribution of seafloor motion. Seismic networks can rapidly provide this information using analytical relations (Okada, 1985). However, to compute an accurate tsunami model, a detailed estimate of the fault slip distribution and high-resolution bathymetry are necessary (Bletery et al., 2015). With this in mind, methods to rapidly obtain fault slip distribution using combined seismologic and geodetic observations are being developed (e.g. Melgar et al., 2019).

Still, those methods rely on seismic data and one shortcoming of those seismic data is that earthquake magnitudes are often under-estimated by early-warning systems (Ozaki, 2012) and thus the size of the expected tsunami is also under-estimated. Current early warning methods rely heavily on instrumentation near the areas at risk. This instrumentation can be sparse in some areas, e.g., in Myanmar, Indonesia, or Vanuatu (http://www.isc.ac.uk/registries/), and instrument failure can also occur. Data gaps in sparsely instrumented areas thus need to be filled (Okal, 2015).

In this study, we propose a new approach for coseismic deformation localization that takes advantage of the global-scale monitoring capabilities of Global Navigation Satellite Systems (GNSS) networks. During the past two decades, it has become quite common to use GNSS to monitor the impact of large and shallow earthquakes on the ionosphere (e.g. Astafyeva 2019 and references therein). A brief summary of the mechanism behind this new observation is that the rupture of large and shallow earthquakes generates sudden surface displacement, which can strongly excites a pressure wave in the surrounding atmosphere. This triggered acoustic-gravity pressure wave propagates toward the upper atmosphere and affects the ionosphere strongly enough to be detected. A Coseismiclonospheric-Disturbance (CID) is thus detected in the variation of the ionospheric Total Electron Content (TEC), calculated using the geometry-free combination of the carrier phase measurements from dual-frequency GNSS satellite signals (Mannucci et al., 1993, Calais \& Minster,1995). We focus here on the acoustic wave part of this signal, which propagates at the speed of sound, $\sim 1 \mathrm{~km} \cdot \mathrm{s}^{-1}$ at ionosphere heights.

Similar to traditional seismic observations ionospheric observations can be made available rapidly after the initial earthquake rupture, with a primary CID signal arriving as soon as six minutes after rupture when the sounding points are located directly above the acoustic origin (Thomas et al., 2018). However, while seismic records can saturate in the case of big earthquakes, ionospheric records do not saturate. Thus we emphasize that using seismic and ionospheric monitoring simultaneously can be a powerful tool for earthquake and tsunami mitigation.

To address the case of a sparse network of ground stations and to focus on the specific contribution of multi-GNSS, we investigate a configuration with only a single GNSS station. We make use of the multiple GNSS constellations currently operating continuously all over the globe (Ren et al. 2016), i.e., GPS, GLONASS, Galileo, BEIDOU (respectively denoted by the letters G, R, E, C). Hence, 
a single ground station with multi-GNSS reception capability is equivalent to an array of ionospheric receivers whose number corresponds to the number of visible satellites.

The acoustic wave is commonly generated near the earthquake epicentral area (Occhipinti et al., 2013) and several studies have shown that this wave can be modeled numerically using acoustic ray tracing (see Mikesell et al., 2019 and references therein) or more sophisticated methods (Inchin et al., 2020). It has even been observed that for a megathrust earthquake, such as the $2004 \mathrm{Mw} 9.3$ Sumatra-Andaman earthquake that ruptured more than $1300 \mathrm{~km}$ in length, the coseismic ionospheric response was sensitive to the evolution of the rupture (Heki et al., 2006).

We propose to make use of the acoustic wave propagation properties to constrain the location of the vertical surface deformation following an earthquake using TEC data, which complements more classical approaches (e.g., seismological and geodetic) and contributes to tsunami early-warning systems. Several ionospheric studies based on the relocation of CID sources have been done. Afraimovich et al. (2006) with the example of the $2000 \mathrm{Mw} 7.7$ Sumatra earthquake, proposed a secondary source above the epicenter and located it at the height of the maximum of ionization. This observation helped them determine that the area around the epicenter is the source of the observed CID. Later, Liu et al. (2010) used a grid search to minimize the differences of apparent velocities between the observed CID of multiple satellite-station pairs. They relocated the source of the $1999 \mathrm{M}_{\mathrm{w}}$ 7.6 Chi-Chi earthquake between 40 and $130 \mathrm{~km}$ north of the epicenter and demonstrated that the origin of the ionospheric disturbance is located at the ground surface not at the epicenter, but near the maximum of surface deformation. More recently, Lee et al. (2018) introduced a method to locate the acoustic source of the $2016 \mathrm{Mw} 7.8$ Kaikoura earthquake by using the seismological-derived technique of back-projection.

In this study, we present our novel approach to retrieve the acoustic origin of a CID and, by extension, the surface deformation region. Using a synthetic example, we first demonstrate that the CID signature is sensitive to the acoustic source location. We then develop a grid search strategy to test how well we can relocate the CID origin. We show field results from the $2011 \mathrm{Mw} 7.1$ Van (Turkey) earthquake. In a second example, we revisit the complex Kaikoura (New Zealand) earthquake using for the first time, to our knowledge, the combined information of not only GPS and GLONASS, but also Galileo-derived TEC signals.

\section{2- Single station localization - the case of the $2011 \mathrm{Mw} 7.1$ Van earthquake, Turkey}

In this section, we validate our method using the example of the Van earthquake. On October 23rd, 2011, a Mw 7.1 earthquake occurred at 10:41:30 UTC in Turkey near the city of Van. The United States Geological Survey (USGS) locates the epicenter of the event at $38.72^{\circ} \mathrm{N}$ and $43.51^{\circ} \mathrm{E}$ (Fig.

1.a). This event produced moderate deformation of the ground surface with a maximum uplift of 1 meter (Elliott et al., 2013). Significant surface deformation was limited to the area extending from the 
epicenter to $20 \mathrm{~km}$ toward the North with a total longitudinal (EW) extension of $40 \mathrm{~km}$. This earthquake produced a CID visible in the ionosphere eight minutes after the initiation of the rupture. Using only one GNSS station, the current study aims to localize the acoustic source on the ground that causes the observed CID. Since the vertical deformation of this intra-plate earthquake is well constrained by InSAR data and only covers a small area, a point source approximation can be used to model the CID as confirmed by the fairly good reconstruction of the observations by Rolland et al., 2013. At the time of the earthquake, only GPS and GLONASS systems were in operation.

\subsection{Van Coseismic Ionospheric Signature}

To test the localization performance in a region with limited GNSS instrumentation, only one multi-constellation (GPS and GLONASS) station is used for this case study. Here we select one of the available GNSS stations of the Continuously Operating Reference Stations Turkish permanent network. Using multiple stations from this network, Rolland et al. (2013) highlighted that the perturbation waveform is sensitive to the geomagnetic field, i.e., the northern ionospheric sounding points observe a first negative peak of the signal while the southern points observe a positive peak. Following this study, we select a station with a clear coseismic signal among the nine dual-frequency ( $L 1$ and L2 band) stations available. We choose the SIRN station, located $161 \mathrm{~km}$ south of the epicenter because it observes the earliest onset of the coseismic perturbation, 470 seconds (eight minutes) after the earthquake rupture initiation.

We extract and process the 30 seconds sampled TEC time series from the GNSS data of SIRN station following the approach of Rolland et al. (2013). The coseismic signal is highlighted with application of a 2 to $8 \mathrm{mHz}$ band-pass filter. In order to visualize where the coseismic perturbation is sounded, we use the ionospheric thin layer approximation: we consider that the perturbation is sounded at the altitude of the maximum ionization of the ionosphere (derived from the International Reference Ionosphere (IRI), Bilitza et al., 2017). We name the ionospheric pierce point (IPP) the intersection between the thin layer and the satellite-station line-of-sight (LOS). In the present case, this thin layer is set at $280 \mathrm{~km}$ altitude. The closer the IPP is to the acoustic wave source, the more we expect to observe the CID. Five satellites were sounding the ionosphere (from the time of the initiation of the rupture to $1500 \mathrm{~s}$ after) within the model boundary (500 km from a trial source on Earth's surface) and with an elevation above $20^{\circ}$ (see Fig. 1a): three GPS (G21, G29, G30) and two GLONASS (R02, R17) satellites.

In Fig. 1.b we observe for the closest IPPs, G29- and R17-SIRN, a typical CID signature in the variation of filtered STEC (dSTEC): a N-shape pulse (first positive pulse followed by a negative one) arriving about 8-10 min after the earthquake. This specific signature is visible on the time series and is identified by Rolland et al. (2013) as the direct acoustic perturbation generated by the earthquake. The largest pulse is detected by G29-SIRN with a peak amplitude of 0.25 TEC units (TECu). As expected, the pairs G29- and R17-SIRN have the highest dSTEC peak values because they efficiently sound the ionospheric perturbation in the vicinity of and over the epicentral region. The smallest perturbation amplitudes are for satellite-station pairs G21- and G30-SIRN with a peak amplitude of 0.03 TECu and 
$0.02 \mathrm{TECu}$, respectively. Those values are close to the noise level, estimated at 0.02 TECu during this time. The G21 and G30 IPP, as well as the R02 IPP, are south of the rupture, all roughly $250 \mathrm{~km}$ from the epicentral area. A small dSTEC amplitude like this can be explained by destructive interference during integration of the signal (Heki \& Ping, 2005; Bagiya et al., 2019) in the range of $50^{\circ}$ to $60^{\circ}$ of elevation in the southern direction. Finally, except for R02-SIRN, Rolland et al. (2013) show that it is possible to successfully model the CID associated with the Van earthquake.

\subsection{Forward modeling}

We use the lonoSeis numerical model developed by Rolland et al. (2013) and Mikesell et al. (2019). This model rapidly reconstructs the main features of the integrated electron density perturbation (sTEC) associated with an impulsive event. The sudden deformation of the ground generates compressional (acoustic) waves that propagate up to the ionosphere. This perturbation is modeled in an ad-hoc way, assuming an acoustic N-shape wave (Fitzgerald, 1997; Heki and Ping, 2005;

Dautermann et al., 2009). We assume that the origin of this wave is, to first order, a point source at the Earth's surface, which generates an acoustic wave that propagates in all directions in the atmosphere. Numerous observational and modeling studies demonstrate the formation of coseismic acoustic shocks in this setting (e.g. Zettergren \& Snively, 2015; Chum et al., 2016; Astafyeva et al., 2019; Inchin et al., 2020). The lonoSeis simulation accounts for the non-linear lengthening of the acoustic pulse due to the absorbing atmosphere, but does not account for the faster speed of propagation of the leading shock of the $\mathrm{N}$-wave or other complex waveform effects.

To compute the acoustic wave amplitude and arrival time at a given altitude we use acoustic ray tracing. The result is convolved with a source-time function chosen as the first derivative of a Gaussian after Dautermann et al. (2009). Specifically, the initial motion of the atmosphere can be describe in time through the velocity $v\left(m . s^{-1}\right)$ of the neutral particles (see Fig. A1) as:

$v(\vec{r}, t)=A_{z}(\vec{r}) \frac{A_{0} \sqrt{2}}{\sigma(t)^{3 / 2} \pi^{1 / 4}}\left(t-t_{0}\right) e^{\frac{-\left(t-t_{0}\right)^{2}}{\sigma(t)^{2}}}$,

where $\vec{r}$ is the position vector (relative to acoustic source location at Earth's surface), $t$ is the propagation time along the acoustic beam, $t_{0}$ is the time of maximum particle motion, $A_{0}$ is a constant that represents the initial amplitude of the waveform, referred to here as the scaling factor, and $A_{Z}$ is an amplitude factor that describes how the phase and amplitude are affected by frequency-dependent attenuation with altitude after Garcia et al. (2005). The coefficient $\sigma=a+b t$ models the effect of the dispersive attenuation on the phase of the wave with $a$ the duration of the initial pulse, $b$ the pulse expansion coefficient over time, referred to here as the broadening factor.

The model generates an acoustic wave at the initiation time $\left(t=t_{i}\right)$ of the rupture. Then, the wave is propagated in a realistic atmosphere (NRLMSISE-00, Picone et al., 2002), ionosphere (IRI, Bilitza et al., 2017) and geomagnetic field (IGRF, Thébault et al. 2015) with 3-dimensional ray tracing in a stratified atmosphere (Dessa et al., 2005). An ionospheric coupling scheme is then used to compute the electron density perturbation, and we integrate the electron density perturbation along the LOS between 150 and $490 \mathrm{~km}$ of altitude, using a satellite orbit product delivered by the IGS (International 
GNSS Service). Simulation parameters are presented in Table 1 and correspond to the location and time of the earthquake with the broadening factor $(b)$ and the scaling factor $\left(A_{0}\right)$ needed to fit the observed pulse duration and its amplitude, respectively. The simulation uses a trial source at the epicenter in Table 1. A larger $b$ accounts for the longer perturbation as in the case of an earthquake of larger magnitude (Astafyeva et al. 2013).

The resulting waveforms are detrended, and we highlight the perturbation of interest using the same filter as for the observed data. The modeled time series are shown in Fig. $1 \mathrm{~b}$ for three source locations and along with the observed dSTEC perturbation. The input source locations are 1) the

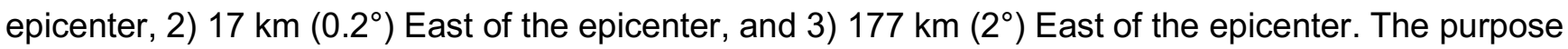
of these different locations is to highlight the delay of up to $180 \mathrm{~s}$ ( 3 minutes) on the main pulse and the variation of the amplitude of the signal due to different acoustic source locations. Overall, we expect the largest amplitudes at the closer ionospheric receivers (i.e., R17- and G29-SIRN), but the non-tectonic factors of the observation geometry and the dominant alignment of plasma drift with the geomagnetic field lines also alter the amplitude. For the first non-tectonic factor, Heki \& Ping (2005), Rolland et al. (2013), and Bagiya et al. (2019) show that the optimal configuration is obtained where the LOS is perpendicular to the wave vector, which enables the constructive LOS integration of the TEC along the acoustic wave-driven plasma disturbance (i.e., parallel to the wavefront).

Here, the observed signals from the closest IPPs are best modeled from a source at the epicenter, which is not the case for signals from G21-, G30-, and R02-SIRN, where IPPs are more than $200 \mathrm{~km}$ from the epicenter and the observed maximum of dSTEC is close to the noise level. As expected, when the source is moved away from the IPP measurement point, the perturbation is delayed in time. More interestingly, moving the source can induce a counter-intuitive variation of the amplitude of the time series. For G29-SIRN, we observe a $\sim 10 \%$ increase in the amplitude between the series modeled at the epicenter and $17 \mathrm{~km}\left(0.2^{\circ}\right)$ eastward. In contrast this difference is roughly a $50 \%$ decrease at $177 \mathrm{~km}\left(2^{\circ}\right)$ eastward from the epicenter for R17-SIRN. For R02-SIRN, the opposite occurs with an increase of the amplitude when the distance between the source and the receiver increases. These forward modeling results highlight that the amplitude does not follow a simple geometric decay relationship when the source location is shifted away from the measurement point. As this effect is not fully characterized, in the next steps, we adjust the amplitude of each series on the corresponding data using the ratio of the accumulated energy (Appendix A1).

\subsection{The grid search method applied to synthetic data}

In this study, the search for the best-fitting surface deformation region is a non-linear problem that we solve with a grid search. Thanks to the model performance in time and computing power, this method allows us to explore the parameter space and to map misfit rapidly. This enables identification of a preferred region for the CID origin by searching for the minimum misfit between observed and synthetic time series. We build a $4^{\circ} \times 4^{\circ}$ grid $(\sim 350 \mathrm{~km} \times 450 \mathrm{~km})$ centered on the epicenter with a $0.2^{\circ}$ step $(\sim 20 \mathrm{~km})$ between grid nodes. Each node of this grid is used as an input for a forward model, with the acoustic perturbation initiated at $t_{i}$, and the amplitude of the synthetic waveform adjusted to match 
the amplitude of the observations (Appendix A). The synthetic observations are created using the parameters in Table 1 (source at the epicenter), except for parameter $A_{0}$ (provided in Table A1), which is based on the real observations. The misfit of each tested model is evaluated by computing the Root Mean Square Error (RMSE) for each station-satellite pair, where no noise is added to the synthetic series.

The RMSE maps computed for the individual synthetic data observations (referred to as synthetic maps) use the synthetic time series generated by an acoustic source at the epicenter as the observed series (Fig. 2). As expected, the minimum RMSE for each satellite-station pair corresponds to the case where the trial source is at the epicenter. The individual synthetic maps tend to exhibit the lowest RMSE values along a circle centered on the ionospheric sounding zone and crossing the epicenter test source. The RMSE maps built from G29- and R17-SIRN synthetic observations illustrate this feature. As R17-SIRN sounds the ionosphere just above the test source, the best-fit circle has a much smaller radius than the best-fit circle of the G29-SIRN satellite-station pair. The maps built with G21-, G30-, R02-SIRN show an even larger circle because the measurement is made at a further distance from the source, i.e., the IPP is further from the true source position.

Figure 3a shows the resulting RMSE map from the combination of the useful satellites (i.e., the RMSE computed for the entire dataset merged in a single time series of length = number of sample per satellite $x$ number of satellites), from which we can identify the most probable zone of the acoustic source location. As expected, in this synthetic case, we retrieve the location of the acoustic source at the epicenter test source. Assuming the cost-function is close to a 2D Gaussian distribution (see appendix Fig. A2), we compute the standard deviation of the Gaussian to estimate a confidence interval: roughly $+/-40 \mathrm{~km}$ in latitude and $+/-80 \mathrm{~km}$ in longitude. In other words, the single-station GNSS ionospheric network here enables us to resolve the acoustic source location better in latitude than in longitude.

\subsection{The grid search method applied to field observations}

In this section, we apply the procedure described in Section 2.3 to the observed CID data. We use the same filter between the observations and the synthetics. As suggested in Section 2.3, using only one GNSS station allows locating the acoustic source of the ionospheric perturbation. When we compare the RMSE maps from the synthetic test with the one obtained using real observations, we find many similarities in the patterns. R17- and G29-SIRN clearly delineate a narrow, well-resolved, bestfitting zone. At the same time, maps made with R02-, G21- and G30-SIRN display less resolution and little energy. The minimum RMSE is higher ( 0.04 TECu) than for the synthetic case due to noise in the observed data.

Combining the five satellite measurements (Fig. 3b) leads to a minimum RMSE located at $38.92^{\circ} \mathrm{N}, 42.91^{\circ} \mathrm{E}, 56 \mathrm{~km}$ north-west of the USGS epicenter $\left(38.72^{\circ} \mathrm{N}, 43.51^{\circ} \mathrm{E}\right)$. This value for the observed data lies within a $1 \sigma$ confidence region roughly $50 \mathrm{~km}$ in latitude and $100 \mathrm{~km}$ in longitude, which is as expected slightly larger than in the synthetic case. Figure $3 c$ shows the observed time series and the modeled time series at the minimum of misfit in contrast to the model at the epicenter. 
Although the misfit is lower, the difference in the fit is not significant. This is suggested by the RMSE map which shows that the epicenter is in fact within the confidence area. We remind the reader that this moderate earthquake only deformed the ground near the epicenter, in an area located less than $20 \mathrm{~km}$ North-West of the epicenter (Eliott et al., 2013), which is below the resolution of the approach we propose.

These results also suggest that the localization is affected by a systematic error, a bias corresponding to the shift to the west. Indeed, a similar western shift also affects the best fit region of the synthetic misfit map, suggesting that the bias is partly caused by the ionospheric sounding array geometry. Better azimuthal coverage of stations should help to solve this problem, as shown in the multiple station study of Rolland et al. (2013). Correction of this geometric bias should improve the accuracy of the localization with a single station, while we have demonstrated that a single ground station observing five GNSS satellites has the capability to infer the zone from which the coseismic acoustic waves originate in the case of an earthquake of intermediate magnitude (Mw7.1).

\section{3- Single station localization in the case of the complex 2016 Mw7.8 Kaikoura earthquake, New Zealand}

A strong earthquake of magnitude Mw 7.8 occurred at 11:02:56 UTC on November 13, 2016, near the city of Kaikoura, New Zealand. The USGS reported that the seismic rupture initiated at $42.73^{\circ}$ $\mathrm{S}, 173.06^{\circ} \mathrm{E}$ at $15.1 \mathrm{~km}$ depth and propagated northward along multiple-segments of faults. The surface deformation is well-constrained on land from InSAR and GNSS position data (Hamling et al., 2017). Due to the rupture area being close to the ocean, significant off-shore uplift also generated a tsunami wave that reached $4 \mathrm{~m}$ at the Kaikoura tide gauges (Bai et al., 2017). In addition to six GPS satellites and four GLONASS satellites, two satellites from the recent Galileo constellation were visible from the epicentral area and observed a coseismic ionospheric perturbation (Holding, 2017). These conditions allow us to test how well the GNSS single-station localization method performs on a more complex and longer earthquake rupture, with twice the number of satellites that were available at the time of the Van earthquake.

\subsection{Kaikoura Coseismic Ionospheric Signature}

New Zealand is instrumented by a dense permanent GNSS network maintained by GeoNet New Zealand. All stations are at least bi-constellation (GPS and GLONASS), and nearly 20 were also compatible with the Galileo system during the time of the Kaikoura earthquake. We use the same TEC extraction method as for the Van earthquake above for GPS and GLONASS data and use measurements on the L1 and L5 bands for the Galileo data.

As in the Van study, we focus our analysis on a single station. Here we choose the KAIK GNSS station, which is the closest station to the epicenter at about $52 \mathrm{~km}$ Northeast. Figure $4 \mathrm{a}$ shows the IPP tracks corresponding to the 12 satellites with available data (all satellites have an elevation higher than $20^{\circ}$ ). These radio links form an equivalent ionospheric network of 12 ionospheric receivers characterized by fairly good azimuthal coverage during and after the Kaikoura earthquake. There are four high-elevation $\left(>60^{\circ}\right.$ ) satellite-station pairs: G20-, G29-, R07-, R22-KAIK, and eight low-elevation 
pairs (<60) G05-, G13-, G15-, G21-, R06-, R21-, E08-, E22-KAIK, which cross the ionosphere thin layer (at $320 \mathrm{~km}$ height following Lee et al., 2018) in the vicinity of the epicenter. Because the KAIK station is close to the epicenter, the first group of high-elevation satellites sounds the region directly above the rupture zone. The second group is composed of satellites that sound to the Southwest (G21KAIK), Southeast (R06-, G05-KAIK), Northeast (G15-, G13-, R21-, R22-KAIK) and Northwest (E08$\mathrm{KAIK}$ ) of the epicentral area. Their elevation angles range from $20^{\circ}$ to $40^{\circ}$.

The high-elevation satellites that probe the disturbance have a maximum perturbation amplitude between 0.03 TECu and 0.07 TECu (Fig. 4b). The satellites south of the epicenter have low SNR (the signal amplitude is at the same level as the ambient noise of $0.02 \mathrm{TECu}$ ) with a maximum amplitude between 0.01 and 0.03 TECu except for R06. The satellites north of the epicenter have a high SNR with a maximum amplitude between 0.06 and $0.11 \mathrm{TECu}$. The higher SNR and maximum amplitude values to the North of the epicenter are expected following Lee et al., 2018, who also observed this pattern on multiple stations. The observed TEC signals also show the typical pattern of the direct coseismic acoustic wave TEC signature, with a first positive polarity for the northern ionospheric receivers. Note that a reversed polarity pattern is observed in the northern hemisphere due to the geomagnetic field's action (Rolland et al., 2013; Zettergren \& Snively, 2015). To exclude disturbances outside the expected arrival time of the primary CID, time series are tapered from 300 s to $1800 \mathrm{~s}$.

As previously described, we model the acoustic perturbation generated by the Kaikoura earthquake. The main input parameters of this event are listed in Table 1. For an acoustic source at the epicenter, we have a good fit in arrival time and waveform shape for the high-elevation satellite group (R22-, R07-, G29-, G20-KAIK) that sound the epicentral area. This is consistent with the forward model by Lee et al. (2018) using a trial source located at the epicenter (Fig. 4b). Increasing the distance between the source and the sounding point expectedly leads to later arrival time in the modeled time series. However, the arrival times of the far-away sounding points do not match the observed arrival times. Li et al. (2018) suggest the presence of two distinct acoustic sources, and Lee et al. (2018) show that one of those is at the epicenter, later called the southern source, and the other is at the maximum of deformation, later called northern source. The southern G21-KAIK receiver senses a source closer to its IPP than the epicenter (the synthetic CID computed at the epicenter is delayed with respect to the observation), while the northern R07-KAIK receiver is more sensitive to a source near the epicenter. R06-, G21- and G05-KAIK are at the noise level, also consistent with the simulated perturbations and due to the poor geometry of the recording for these pairs. We expect the northern satellites to be mainly sensitive to the northern source, and thus we perform a grid search to investigate this idea.

\subsection{Kaikoura grid search}

\subsubsection{Locating the surface deformation: a synthetic case}

We apply the grid-search approach to synthetic data following the method presented in section 2.3 for the Van earthquake. The parameters specific to the Kaikoura earthquake such as changes in the time of the rupture and location of the epicenter are reported in Table 1. The changes in the ionospheric environment (i.e., background electron density) are incorporated in the model automatically 
and related to parameters such as the local time (Mikesell et al., 2019). The acoustic source synthetic maps provide an estimate of the resolution we can expect from a perfect observational dataset (for reference, the $A_{0}$ values at the best trial source are available in appendix Table 2). As with the Van earthquake, circular rings of a minimum of misfit intersecting the trial source (here the earthquake epicenter) are present on the individual maps (Fig. 5). This synthetic test highlights the expected contribution of each satellite in the localization. We thus remark that we have 1) a well-resolved localization for low elevation satellites (G15- E22-, E08-) and 2) a poorly resolved localization for the southernmost IPP with SNR close to 1 (G20-, G21-, R06-KAIK). Furthermore, the best resolution is obtained for elevation angles between $40^{\circ}$ and $60^{\circ}$. The RMSE of the combined synthetics allows us to locate the source at the epicenter with a $1 \sigma$ of roughly $+/-30 \mathrm{~km}$ in latitude and $+/-60 \mathrm{~km}$ in longitude (Fig. 6c).

\subsubsection{Locating the surface deformation: real observation case}

Next, we apply our grid-search method to the field observations. A remarkable point is the shift of the best-fit circles towards the North/Northeast of the epicenter (Fig. 5). This shift is small $(\sim 10 \mathrm{~km})$ for G20-KAIK, which sounds the region above the epicentral area. The shift reaches $50 \mathrm{~km}$ for E22KAlK sounding the Northeast region (above the North island) and for G21-KAIK sounding the Southwest region (all of the individual maps are available in Fig. A3). We also compute the combined misfit grid (Fig. 6b). The comparison of the 3-D misfit function with the one computed for the synthetic test shows that for the Kaikoura earthquake event (Fig. A4), the RMSE variation is closer to a Gaussian approximation than the Van earthquake event (Fig. A2), where the Gaussian shape was deformed to the West. However, we must be careful with the interpretation here because the global minimum obviously might not correspond to the best fitting location when each satellite is taken individually (see Fig. A5). The RMSE map computed for all satellites provides the best acoustic source location at $42.34^{\circ} \mathrm{S}, 173.85^{\circ} \mathrm{E}$ (minimum of misfit in Fig. $6 \mathrm{~d}$ ). This source is localized with a $1 \sigma$ uncertainty of about $+/-50 \mathrm{~km}$ in latitude and -50 to $+170 \mathrm{~km}$ in longitude.

Seismo-geodetic studies of the Kaikoura earthquake (Bai et al., 2017; Hamling et al., 2017) show that the maximum uplift was about $48 \mathrm{~km}$ Northeast of the epicenter (around $42.1^{\circ} \mathrm{S}, 174.0^{\circ} \mathrm{E}$ ) and inland. Considering this uplift as the main acoustic source, the shift between the best-fit trial source and the uplift (48 $\mathrm{km}$ ) provides an estimate of our grid search method accuracy.

\section{4- Discussion:}

Using the grid-search method with field observations, we provide a first evaluation of the capability to localize the origin of CIDs using only one ground-based GNSS station and assuming it coincides with the maximum surface deformation. The resolution of the CID source localization for the Kaikoura earthquake $(1 \sigma \approx 50 \times 110 \mathrm{~km})$ is comparable to the Van earthquake $(1 \sigma \approx 50 \times 90 \mathrm{~km})$. For both case studies, we find a better resolution in the latitude direction than in the longitude direction. We propose that this is because the number of IPPs in the latitudinal direction is larger than in the 
longitudinal direction (i.e. the semi-minor axis of the confidence ellipse is in the direction of the higher number of satellites). Shifts between the retrieved point source and the known area of maximum uplift are $53 \mathrm{~km}$ and $48 \mathrm{~km}$ for Van and Kaikoura earthquakes, respectively. In the case of the extended Kaikoura rupture, the retrieved CID source location allows us to assess the northward preferential direction of the rupture and further, to set a lower bound on the extension of the rupture and its direction (95 km +/- $50 \mathrm{~km}$ northward).

The precision and geometry of this confidence ellipse strongly depend on the orbital configuration of the GNSS constellations, as it does for standard GNSS positioning precision (e.g., Zumberge et al., 1997). We demonstrate that satellites between $40^{\circ}$ and $60^{\circ}$ of elevation offer better precision than low angle satellites $\left(<40^{\circ}\right)$. The high-elevation satellites are more sensitive to the dynamic modification of the ionosphere induced by the acoustic wave. We hypothesize that increasing the number of GNSS satellites improves the performance of the localization, and we investigate this with two sensitivity tests.

We first test how the distribution of satellites affects the solution by comparing the localization result of the Kaikoura earthquake with and without the new Galileo system. The use of GPS and GLONASS data only, provides a $1 \sigma$ of $70 \times 200 \mathrm{~km}$ compared to the $1 \sigma$ of $50 \times 110 \mathrm{~km}$ obtained with two additional Galileo satellites. We attribute this factor of two improvement of the longitudinal precision to the better azimuthal coverage offered by satellite E08, which happens to be the only one crossing the Northwest quadrant at low elevation. This behavior is also observed with the synthetic data. However, we note that the improvement in precision seems to decrease the accuracy of the solution as the best-fit trial source is shifted by $80 \mathrm{~km}$ toward E08 when this IPP is added to the grid-search.

Second, to get a sense of the sensitivity of the method to the station location, we apply the single-station localization method to other stations. For the case of the Van earthquake we select station MURA, located $\sim 30 \mathrm{~km}$ northeast of the epicenter (Fig. A6). The MURA station locates the acoustic source with better precision $(1 \sigma \approx 50 \times 70 \mathrm{~km}$, versus $50 \times 100 \mathrm{~km})$ and accuracy (38 $\mathrm{km}$ from the epicenter vs $53 \mathrm{~km}$ ). We explain this enhanced precision and accuracy by the better azimuthal coverage of the IPPs around the epicenter. This indicates that the performance of the method is dependent on the ionospheric array coverage, which is dictated by the position of the station and the satellites at the time of sensing.

Further studies are needed to assess how the method performs when the maximum uplift is located at a far distance from the station. This specific question is critical in subduction zones where the distance between the earthquake and the station can be quite large. Subduction mega-thrust earthquakes generate significant uplift on-shore, but also off-shore and sometimes up to the trench at distances reaching a few hundred kilometers (Sladen \& Trevisan, 2018). To test this idea, we computed the synthetics misfit maps using a synthetic case where the source is located about $350 \mathrm{~km}$ from the station (to the Northeast Fig. A7a and to the Southeast Fig. 7b). The results indicate a confidence area similar in shape to the other synthetic cases. These results are coherent with the theoretical resolution limit of the method, which is approximately a quarter of the observed wavelength (Kallweit and Wood, 
1982). Considering a 4-minute period acoustic wave propagating at $1 \mathrm{~km} / \mathrm{s}$, the theoretical resolution limit of the method is $+/-30 \mathrm{~km}$.

The grid-search example using station WAIM (located $317 \mathrm{~km}$ Southwest of the Kaikoura earthquake epicenter, Fig. $5 e$ and $5 f$ ) allows us to explore the limitations of the method in realistic conditions. The location of WAIM is unfavorable regarding the northern directivity of the CID due to the geomagnetic field and also regarding the Northeastward propagation of the rupture. This station offers a coverage of 9 satellites (Table A2) with a clear coseismic signature only for the Northeastern low elevation satellites sounding above the epicentral area (G13,G15,R21,E22, Fig. A8). Those unfavorable CID monitoring conditions explain why the retrieved best-fit zone is larger than for KAIK $(+/-200 \mathrm{~km})$ as well as the poor accuracy $(100 \mathrm{~km}$ in the direction of the station). Nevertheless, this result is consistent with a CID originating from the surface deformation in the epicentral area and highlights the importance of the observation geometry (distance and azimuth angle) with respect to the searched deformation zone.

The model assumptions used in this study might also affect the result. Finite source contributions are not modeled; we do not account for the rupture propagation, fault heterogeneity, or surface waves. This is a potential reason why we fit the Van ionospheric observations better than the Kaikoura observations; Van was a less complex earthquake. In the work here, we set the initiation time of the acoustic wave equal to the initiation time of the rupture. In future studies, the onset time of the acoustic pulse could be estimated with the constraint that it must be later than the centroid (i.e. rupture) time.

In addition, a larger distance between the source and the IPP can decrease the fit quality due to accumulating errors in the modeled TEC phase arrival (Lee et al., 2018; Mikesell et al., 2019). This delay can reach up to $1.3 \mathrm{~min}$ for an IPP at about $500 \mathrm{~km}$ from the source, where the STEC perturbation arrives 20 minutes after the rupture (Mikesell et al. 2019). As it is a systematic delay probably linked to the non-linear behavior of the acoustic shock wave (Inchin et al., 2020), this could also be taken into account by estimating an effective (non-physical) sound speed, that would also include the directional effects of horizontal winds. Future enhancements of the physical model should try to account for this delay, which would improve the accuracy of the grid-search method presented here. Another path forward to improve the quality of the localization would be to jointly invert for the amplitude scaling factor and not simply adjust it for each time-series as done in this study. These developments are necessary to make use of higher frequency data $(1-\mathrm{Hz})$ and access the space-time evolution of the surface deformation (Heki et al. 2006; Inchin et al. 2020).

As a final though on how well the single-station method performs, we refer to the study of Lockman \& Allen (2005) who investigated the accuracy of single-station determination of an earthquake epicenter location using P-wave arrivals. In the best configurations, the errors in the distance and backazimuth determination are $+/-15 \mathrm{~km}$ and $+/-20^{\circ}$, respectively. Multi-station epicenter determination accuracies range from 5 to $25 \mathrm{~km}$ for local to teleseismic networks (Bondar et al., 2004). Comparatively, with good ionospheric network conditions, our single multi-GNSS station method seems to be able to locate the main coseismic surface deformation zone with reasonable accuracy $(+/-50 \mathrm{~km})$. 


\section{5- Conclusion:}

This study demonstrates that it is possible to localize the ground location associated with the origin of the observed CIDs with a well-located single dual-frequency GNSS station. We develop an approach that uses a grid-search of the source location via modeling of the coseismic acoustic wave propagating from the ground to the ionosphere and coupling into the ionosphere electron density. We assess the accuracy of the method by comparing our preferred (best-fit) location to the maximum surface uplift location for two case studies. We find an accuracy of $\sim 50 \mathrm{~km}$ in the Van and Kaikoura case studies and a theoretical precision of the same order.

We also determine that the precision of the localization strongly depends on the satellite geometrical coverage. This can be improved, if not with a well-placed station, with the number of observed satellites. We emphasize that the addition of a few extra ground-based GNSS stations can be useful to reduce the error and uncertainty of the localization of the acoustic source. The corresponding data should be incorporated as they become available in an early-warning ionosphere-based dataset.

This method can be used to identify the main acoustic source (within a certain confidence interval) on land or at sea for shallow earthquakes of large magnitude (typically $M>7$ ) producing a clear CID. Positive detections were reported for tens of earthquakes with the lowest magnitude of 6.6 and maximum depth of $50 \mathrm{~km}$ (Cahyadi \& Heki, 2015). With a single GNSS station, the resolution offered by this grid search method applied to the Kaikoura case is sufficient to provide first-order information about a Mw 7.8 earthquake rupture process within 20 minutes after its initiation. In the case of this extended rupture, using a well-placed station, we could recover the northward preferential direction of rupture and set a lower bound on the extension of the rupture and its direction (95 km +/- $50 \mathrm{~km}$ northward). However, further studies are still needed to assess the limit of our point-source approximation when some large earthquake ruptures can be distributed along several hundred kilometers. The Kaikoura earthquake ionospheric response is complex; however, the results show that our method allows us to determine and discriminate the major surface displacement area induced by this earthquake. In summary, this method shows promising and encouraging results toward the establishment of a tsunami monitoring system leveraging the existing global network of GNSS stations, which can even perform in areas with sparse station coverage.

\section{Acknowledgements}

We thank the Continuously Operating Reference Stations Turkish permanent network (Tusaga-Aktif) and GEONET New Zealand for providing the GNSS data used in this study. We also acknowledge the GNSS-TEC package (https://github.com/gnss-lab/gnss-tec) and help from Edhah Munaibari. This study is part of the $\mathrm{PhD}$ work of $\mathrm{FZ}$ supervised by LR, BD, and AS. FZ carried out data analysis and modeling, prepared and interpreted the results and drafted the text. LR conceptualized the study, collected the GNSS data, interpreted the results, and co-drafted the text. TDM hosted FZ two weeks in Boise for in-depth learning of lonoSeis software as the basis of the methodology proposed in the paper. TDM, AS, and BD revised early versions of the manuscript. CT provided support for the grid-search inversion. PC revised the master thesis work at the origin of the present study and provided expertise 
on the ionosphere. All authors added inputs to the design of the work, participated in the interpretation of results, and contributed to the review and editing of the article. We acknowledge support from French Space Agency CNES (Centre National d'Etudes Spatiales), Observatoire de la Côte d'Azur and Université Côte d'Azur Investissement d'Avenir Idex project funded by ANR (Agence Nationale de la Recherche). CT was funded by the ANR JCJC E-POST (ANR-14-CE03-002-01JCJC EPOST) and by the European Research Council (ERC grant agreement No. 805256). We acknowledge the two anonymous reviewers for their critical and thorough comments. 


\section{REFERENCES}

Afraimovich, E.L., Astafieva, E.I., Kirushkin, V.V ., 2006. Localization of the source of ionospheric disturbance generated during an earthquake. International Journal of Geomagnetism and Aeronomy 6. https://doi.org/10.1029/2004GI000092

Astafyeva, E., 2019. Ionospheric Detection of Natural Hazards. Reviews of Geophysics 57, 1265-1288. https://doi.org/10.1029/2019RG000668

Astafyeva, E., Shalimov, S., Olshanskaya, E., Lognonné, P., 2013. Ionospheric response to earthquakes of different magnitudes: Larger quakes perturb the ionosphere stronger and longer. Geophysical Research Letters 40, 1675-1681. https://doi.org/10.1002/grl.50398

Bagiya, M.S., Sunil, A.S., Rolland, L., Nayak, S., Ponraj, M., Thomas, D., Ramesh, D.S., 2019. Mapping the Impact of Non Tectonic Forcing mechanisms on GNSS measured Coseismic Ionospheric Perturbations. Scientific Reports 9. https://doi.org/10.1038/s41598-019-54354-0

Bai, Y., Lay, T., Cheung, K.F., Ye, L., 2017. Two regions of seafloor deformation generated the tsunami for the 13 November 2016, Kaikoura, New Zealand earthquake. Geophysical Research Letters 44, 6597-6606. https://doi.org/10.1002/2017GL073717

Bilitza, D., Altadill, D., Truhlik, V., Shubin, V., Galkin, I., Reinisch, B., Huang, X., 2017. International Reference Ionosphere 2016: From ionospheric climate to real-time weather predictions: IRI-2016. Space Weather 15, 418-429. https://doi.org/10.1002/2016SW001593

Bletery, Q., Sladen, A., Delouis, B., Mattéo, L., 2015. Quantification of Tsunami Bathymetry Effect on Finite Fault Slip Inversion. Pure and Applied Geophysics 172, 3655-3670. https://doi.org/10.1007/s00024-015-1113-y

Calais, E., Minster, J.B., 1995. GPS detection of ionospheric perturbations following the January 17, 1994, Northridge Earthquake. Geophysical Research Letters 22, 1045-1048. https://doi.org/10.1029/95GL00168

Cahyadi, M.N., Heki, K., 2015. Coseismic ionospheric disturbance of the large strike-slip earthquakes in North Sumatra in 2012: Mw dependence of the disturbance amplitudes. Geophysical Journal International 200, 116-129. https://doi.org/10.1093/gji/ggu343

Chum, J., Cabrera, M.A., Mošna, Z., Fagre, M., Baše, J., Fišer, J., 2016. Nonlinear acoustic waves in the viscous thermosphere and ionosphere above earthquake. Journal of Geophysical Research: Space Physics 121, 12,126-12,137. https://doi.org/10.1002/2016JA023450

Dautermann, T., Calais, E., Lognonné, P., Mattioli, G.S., 2009. Lithosphere ,atmosphere, ionosphere coupling after the 2003 explosive eruption of the Soufriere Hills Volcano, Montserrat. Geophysical Journal International 179, 1537-1546. https://doi.org/10.1111/j.1365-246X.2009.04390.x

Elliott, J.R., Copley, A.C., Holley, R., Scharer, K., Parsons, B., 2013. The 2011 Mw 7.1 Van (Eastern Turkey) earthquake: 2011. Journal of Geophysical Research: Solid Earth 118, 1619-1637. https://doi.org/10.1002/jgrb.50117

Garcia, R., Lognonné, P., and Bonnin, X. ( 2005), Detecting atmospheric perturbations produced by Venus quakes, Geophys. Res. Lett., 32 , L16205, doi:10.1029/2005GL023558.

Hamling, I.J., Hreinsdóttir, S., Clark, K., Elliott, J., Liang, C., Fielding, E., Litchfield, N., Villamor, P., Wallace, L., Wright, T.J., D’Anastasio, E., Bannister, S., Burbidge, D., Denys, P., Gentle, P., Howarth, J., Mueller, C., Palmer, N., Pearson, C., Power, W., Barnes, P., Barrell, D.J.A., Van Dissen, R., Langridge, R., Little, T., Nicol, A., Pettinga, J., Rowland, J., Stirling, M., 2017. Complex multifault rupture during the 2016 Mw 7.8 Kaikōura earthquake, New Zealand. Science 356, eaam7194. https://doi.org/10.1126/science.aam7194

Heki, K., Otsuka, Y., Choosakul, N., Hemmakorn, N., Komolmis, T., Maruyama, T., 2006. Detection of ruptures of Andaman fault segments in the 2004 great Sumatra earthquake with coseismic ionospheric disturbances. Journal of Geophysical Research 111. https://doi.org/10.1029/2005JB004202 
Heki, K., Ping, J., 2005. Directivity and apparent velocity of the coseismic ionospheric disturbances observed with a dense GPS array. Earth and Planetary Science Letters 236, 845-855. https://doi.org/10.1016/j.eps1.2005.06.010

Holding, D., 2017. Multi-GNSS Vertical Total Electron Content Estimates: Data Analysis and Machine Learning with Python to Evaluate Ionospheric Perturbations from Earthquakes. http://www.derry-holding.com/static/img/Showcase/python gps gnss.pdf

Inchin, P. A., Snively, J. B., Zettergren, M. D., Komjathy, A., Verkhoglyadova, O. P., \& Tulasi Ram, S. (2020). Modeling of ionospheric responses to atmospheric acoustic and gravity waves driven by the 2015 Nepal 7.8 Gorkha earthquake. Journal of Geophysical Research: Space Physics, 125, e2019JA027200. https://doi.org/10.1029/2019JA027200

Kallweit, R.S., Wood, L.C., 1982. The limits of resolution of zero-phase wavelets. GEOPHYSICS 47, 1035-1046. https://doi.org/10.1190/1.1441367

Lee, R.F., Rolland, L.M., Mikesell, T.D., 2018. Seismo-Ionospheric Observations, Modeling, and Backprojection of the 2016 Kaikōura Earthquake. Bulletin of the Seismological Society of America 108, 1794-1806. https://doi.org/10.1785/0120170299

Li, J.D., Rude, C.M., Pankratius, V., 2018. Characterizing the Complex Two N-Wave Ionospheric Signature of the 2016 Kaikoura Earthquake. Journal of Geophysical Research: Space Physics. https://doi.org/10.1029/2018JA025376

Liu, J.Y., Tsai, H.F., Lin, C.H., Kamogawa, M., Chen, Y.I., Lin, C.H., Huang, B.S., Yu, S.B., Yeh, Y.H., 2010. Coseismic ionospheric disturbances triggered by the Chi-Chi earthquake. Journal of Geophysical Research: Space Physics 115, n/a-n/a. https://doi.org/10.1029/2009JA014943

Lockman, A.B., Allen, R.M., 2005. Single-Station Earthquake Characterization for Early Warning. Bulletin of the Seismological Society of America 95, 2029-2039. https://doi.org/10.1785/0120040241

Mannucci, A.J., Wilson, B.D., Edwards, C.D., 1993. A New method for monitoring the Earth's ionospheric total electron content using the GPS global network. URI: http://hdl.handle.net/2014/36277

Melgar, D., Williamson, A.L., Salazar-Monroy, E.F., 2019. Differences between heterogenous and homogenous slip in regional tsunami hazards modelling. Geophys J Int 219, 553-562. https://doi.org/10.1093/gji/ggz299

Mikesell, T., Rolland, L., Lee, R., Zedek, F., Coïsson, P., Dessa, J.-X., 2019. IonoSeis: A Package to Model Coseismic Ionospheric Disturbances. Atmosphere 10, 443. https://doi.org/10.3390/atmos10080443

National Academies of Science, 2011. Tsunami Warning and Preparedness: An Assessment of the U.S. Tsunami Program and the Nation's Preparedness Efforts. National Academies Press, Washington, D.C. https://doi.org/10.17226/12628

Occhipinti, G., Rolland, L., Lognonné, P., Watada, S., 2013. From Sumatra 2004 to Tohoku-Oki 2011: The systematic GPS detection of the ionospheric signature induced by tsunamigenic earthquakes. Journal of Geophysical Research: Space Physics 118, 3626-3636. https://doi.org/10.1002/jgra.50322

Okada, Y., 1985. Surface deformation due to shear and tensile faults in a half-space. Bulletin of the Seismological Society of America 75, 1135-1154.

Okal, E.A., 2015. The quest for wisdom: lessons from 17 tsunamis, 2004-2014. Philosophical Transactions of the Royal Society A: Mathematical, Physical and Engineering Sciences 373, 20140370. https://doi.org/10.1098/rsta.2014.0370

Ozaki, T. (2012). JMA's Tsunami Warning for the 2011 Great Tohoku Earthquake and Tsunami Warning Improvement Plan. Journal of Disaster Research, 7(sp), 439-445. https://doi.org/10.20965/jdr.2012.p0439

Picone, J.M., Hedin, A.E., Drob, D.P., Aikin, A.C., 2002. NRLMSISE-00 empirical model of the atmosphere: Statistical comparisons and scientific issues. Journal of Geophysical Research: Space Physics 107, SIA 15-1-SIA 15-16. https://doi.org/10.1029/2002JA009430

Ren, X., Zhang, X., Xie, W., Zhang, K., Yuan, Y., Li, X., 2016. Global Ionospheric Modelling using Multi-GNSS: BeiDou, Galileo, GLONASS and GPS. Scientific Reports 6. https://doi.org/10.1038/srep33499 
Rolland, L.M., Vergnolle, M., Nocquet, J.-M., Sladen, A., Dessa, J.-X., Tavakoli, F., Nankali, H.R., Cappa, F., 2013. Discriminating the tectonic and non-tectonic contributions in the ionospheric signature of the 2011, $\mathrm{M}_{\mathrm{w}}$ 7.1, dip-slip Van earthquake, Eastern Turkey. Geophysical Research Letters 40, 2518-2522. https://doi.org/10.1002/grl.50544

Sladen, A., \& Trevisan, J. (2018). Shallow megathrust earthquake ruptures betrayed by their outer-trench aftershocks signature. Earth and Planetary Science Letters, 483, 105-113. https://doi.org/10.1016/j.eps1.2017.12.006

Thébault, E., C. C. Finlay, C. D. Beggan, P. Alken, J. Aubert, O. Barrois, F. Bertrand, T. Bondar,A. Boness, L. Brocco, E. Canet, A. Chambodut, A. Chulliat, P. Cö̈sson, F. Civet, A. Du, A. Fournier,

I. Fratter, N. Gillet, B. Hamilton, M. Hamoudi, G. Hulot, T. Jager, M. Korte, W. Kuang, X. Lalanne, B. Langlais, J.-M. Léger, V. Lesur, F. J. Lowes, S. Macmillan, M. Mandea, C. Manoj, S. Maus, N. Olsen, V. Petrov, V. Ridley, M. Rother, T. J. Sabaka, D. Saturnino, R. Schachtschneider, O. Sirol, A. Tangborn, A. Thomson, L. Tøffner-Clausen, P. Vigneron, I. Wardinski, and T. Zvereva (2015), International Geomagnetic Reference Field: the 12th generation, Earth, Planets and Space, 67(1), 79, doi:10.1186/s40623-015-0228-9.

Thomas, D., Bagiya, M.S., Sunil, P.S., Rolland, L., Sunil, A.S., Mikesell, T.D., Nayak, S., Mangalampalli, S., Ramesh, D.S., 2018. Revelation of early detection of co-seismic ionospheric perturbations in GPS-TEC from realistic modelling approach: Case study. Scientific Reports 8. https://doi.org/10.1038/s41598-018-30476-9

Zumberge, J.F., Heflin, M.B., Jefferson, D.C., Watkins, M.M., Webb, F.H., 1997. Precise point positioning for the efficient and robust analysis of GPS data from large networks. Journal of Geophysical Research: Solid Earth 102, $5005-5017$. https://doi.org/10.1029/96JB03860 
Table

\begin{tabular}{|l|l|l|l|l|l|l|}
\hline $\begin{array}{l}\text { Event } \\
\text { name }\end{array}$ & $\begin{array}{l}\text { Epicenter } \\
\text { Longitude }\end{array}$ & $\begin{array}{l}\text { Epicenter } \\
\text { Latitude }\end{array}$ & $\begin{array}{l}\text { Time } \\
\text { UTC }\end{array}$ & $\begin{array}{l}\text { Broadening } \\
\text { Factor b }\end{array}$ & $\begin{array}{l}\# \\
\text { of Satellites }\end{array}$ & $A_{0}$ \\
\hline VAN & $43.51^{\circ} \mathrm{E}$ & $38.72^{\circ} \mathrm{N}$ & $10: 41: 30$ & 0.04 & 5 & $1.2^{1}$ \\
\hline KAIKOURA & $173.05^{\circ} \mathrm{E}$ & $42.74^{\circ} \mathrm{S}$ & $11: 02: 59$ & 0.06 & 12 & 1 \\
\hline
\end{tabular}

Table 1: Modeling input parameters. ${ }^{1}$ Rolland et al. 2013 
Figures

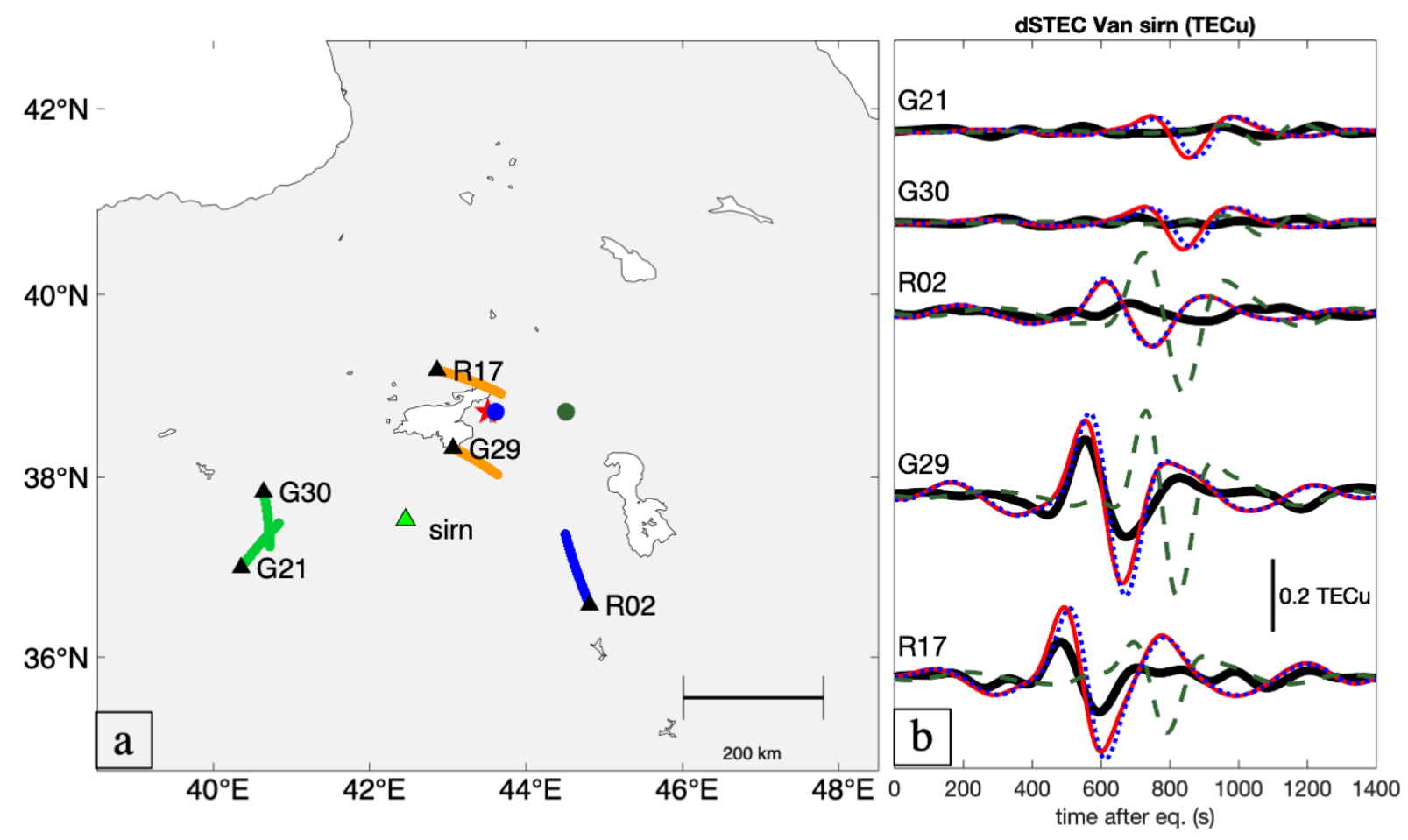

Figure 1 


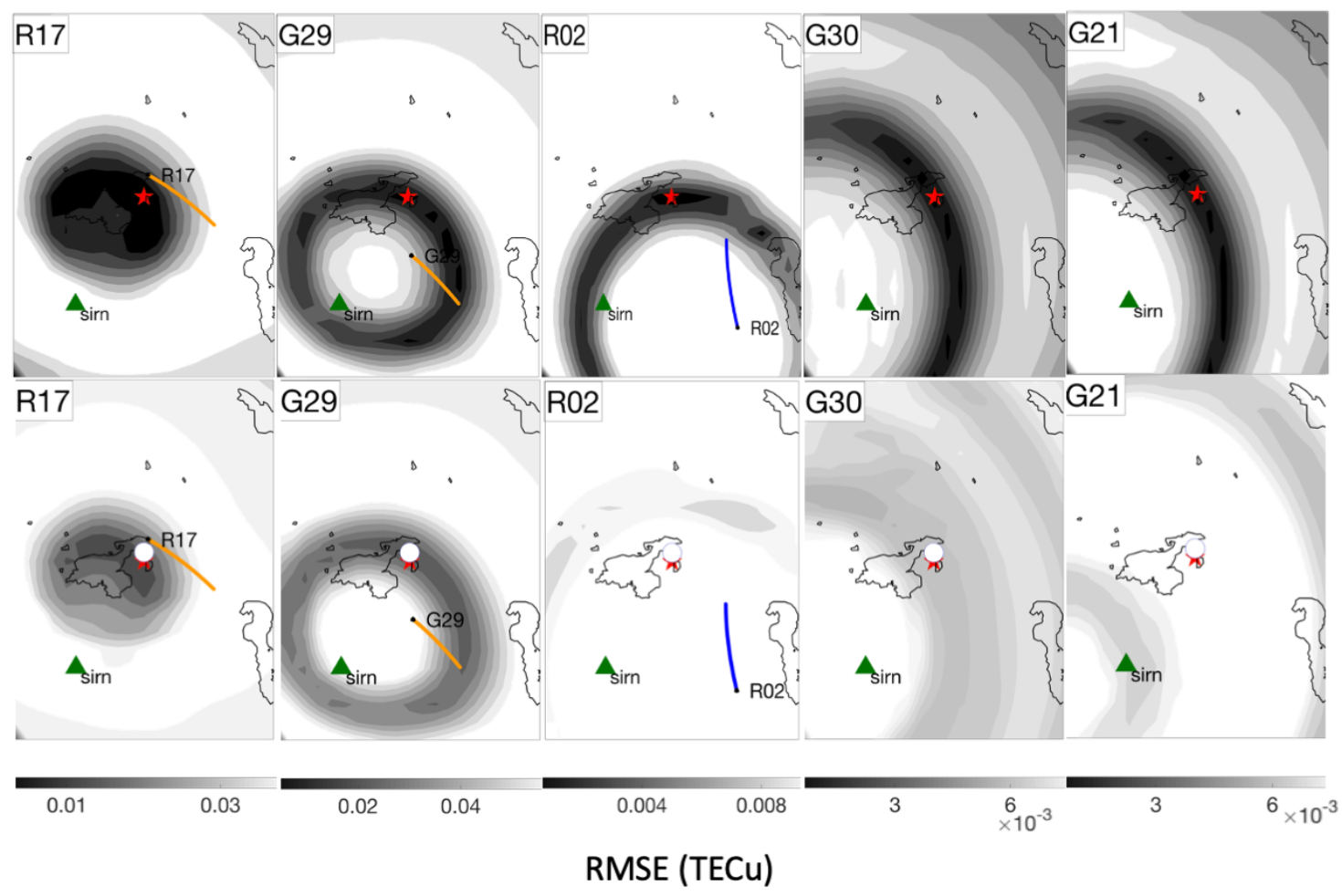

Figure 2 


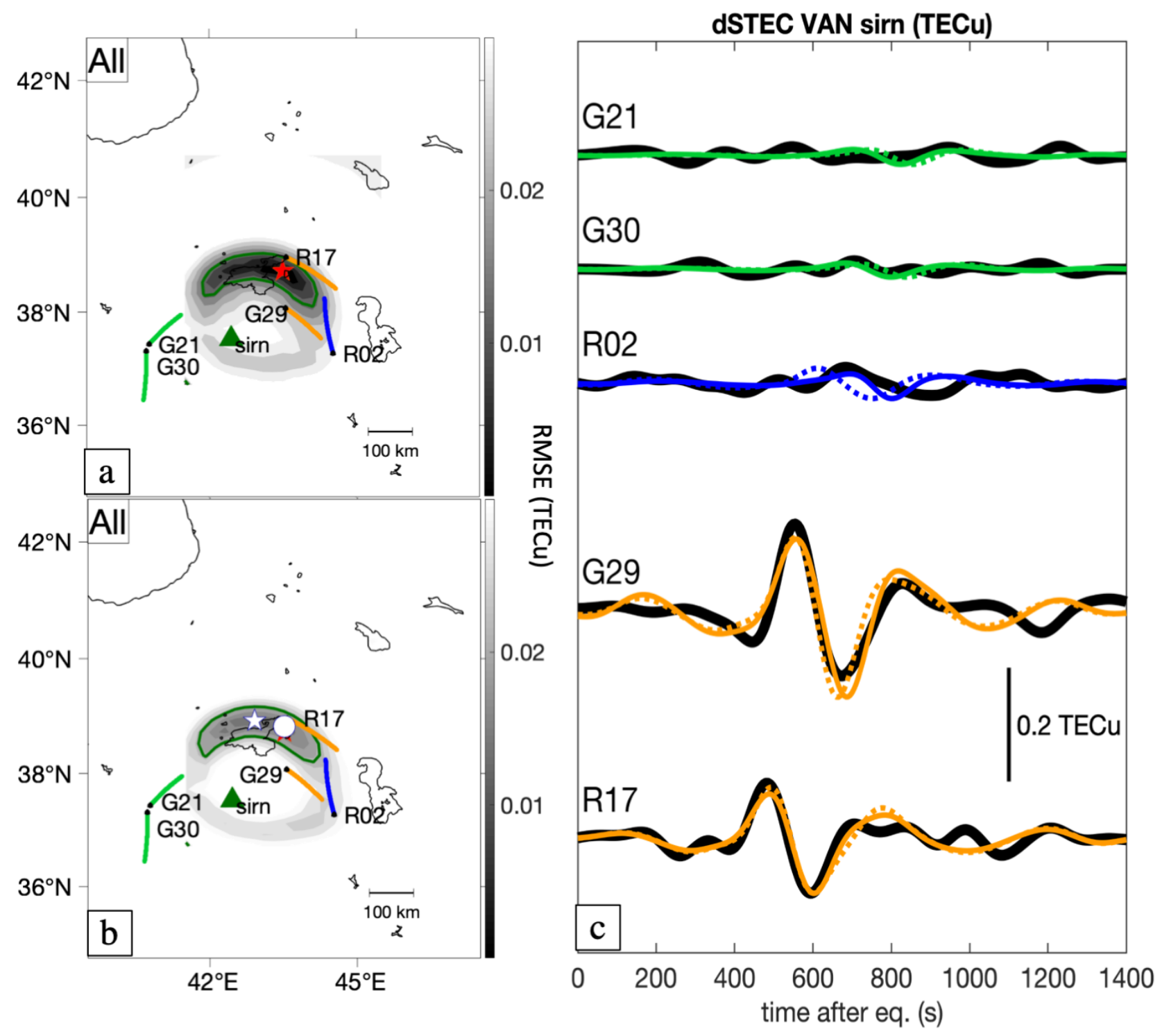

Figure 3 


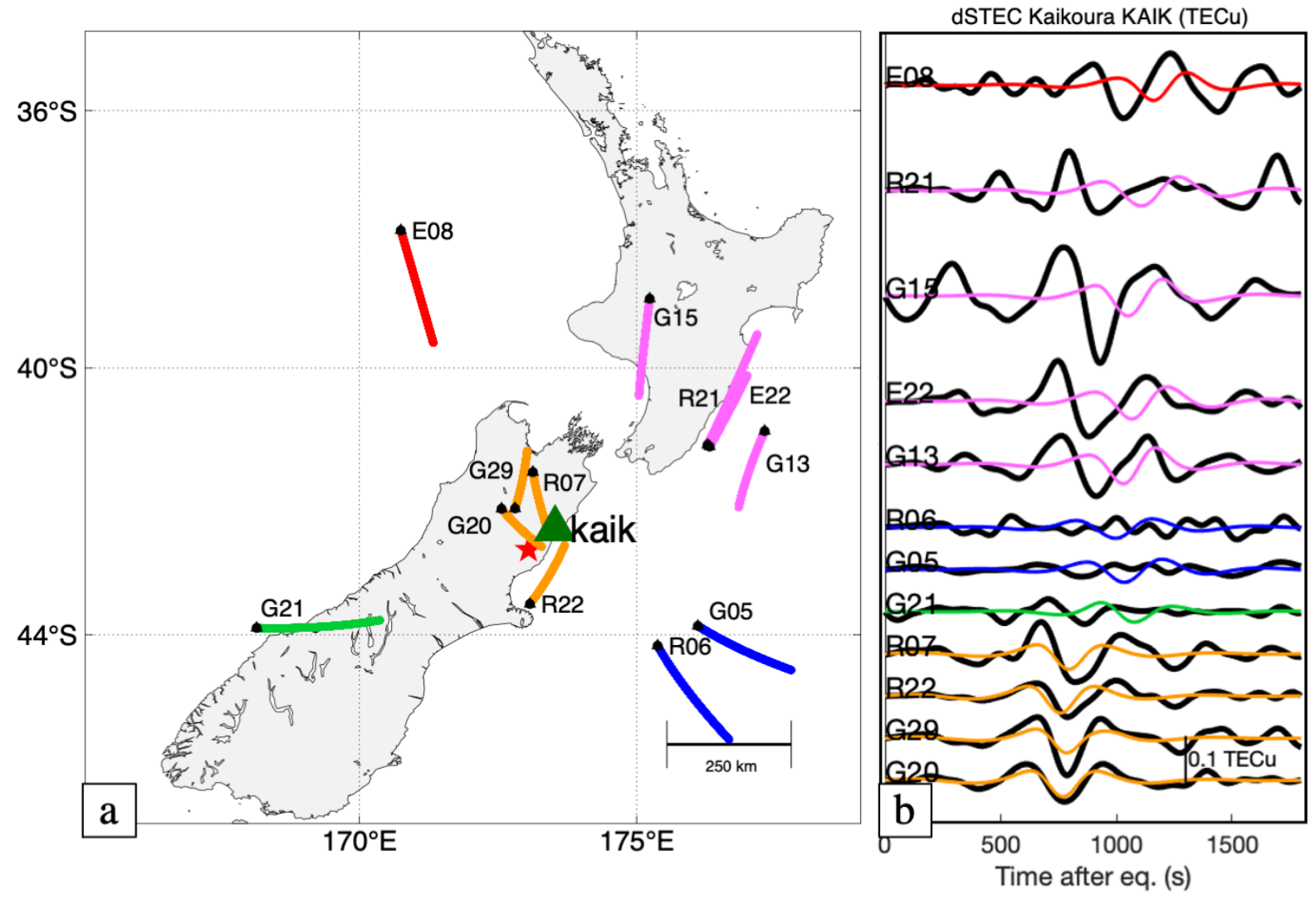

Figure 4 


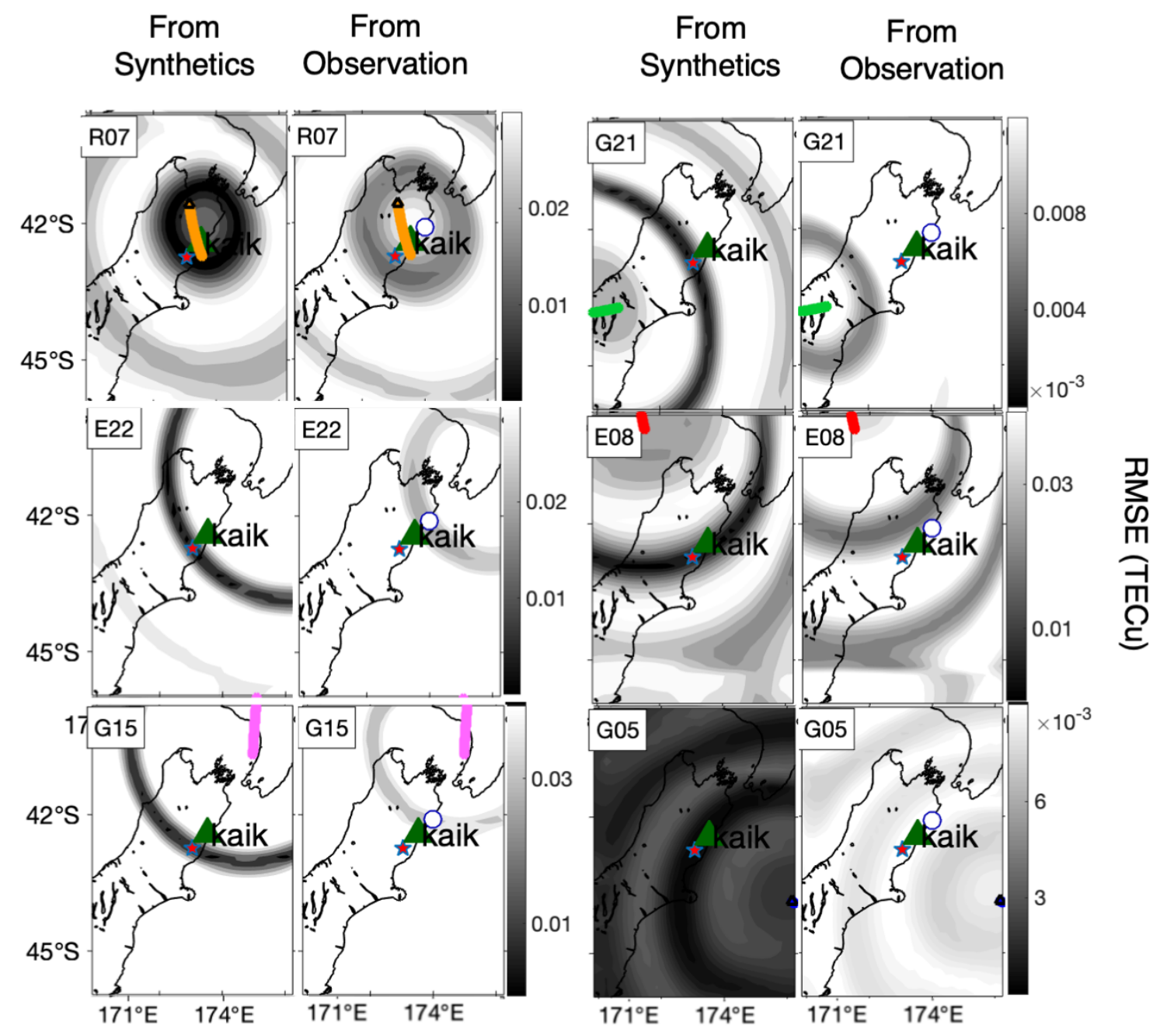

Figure 5 
From

Synthetics

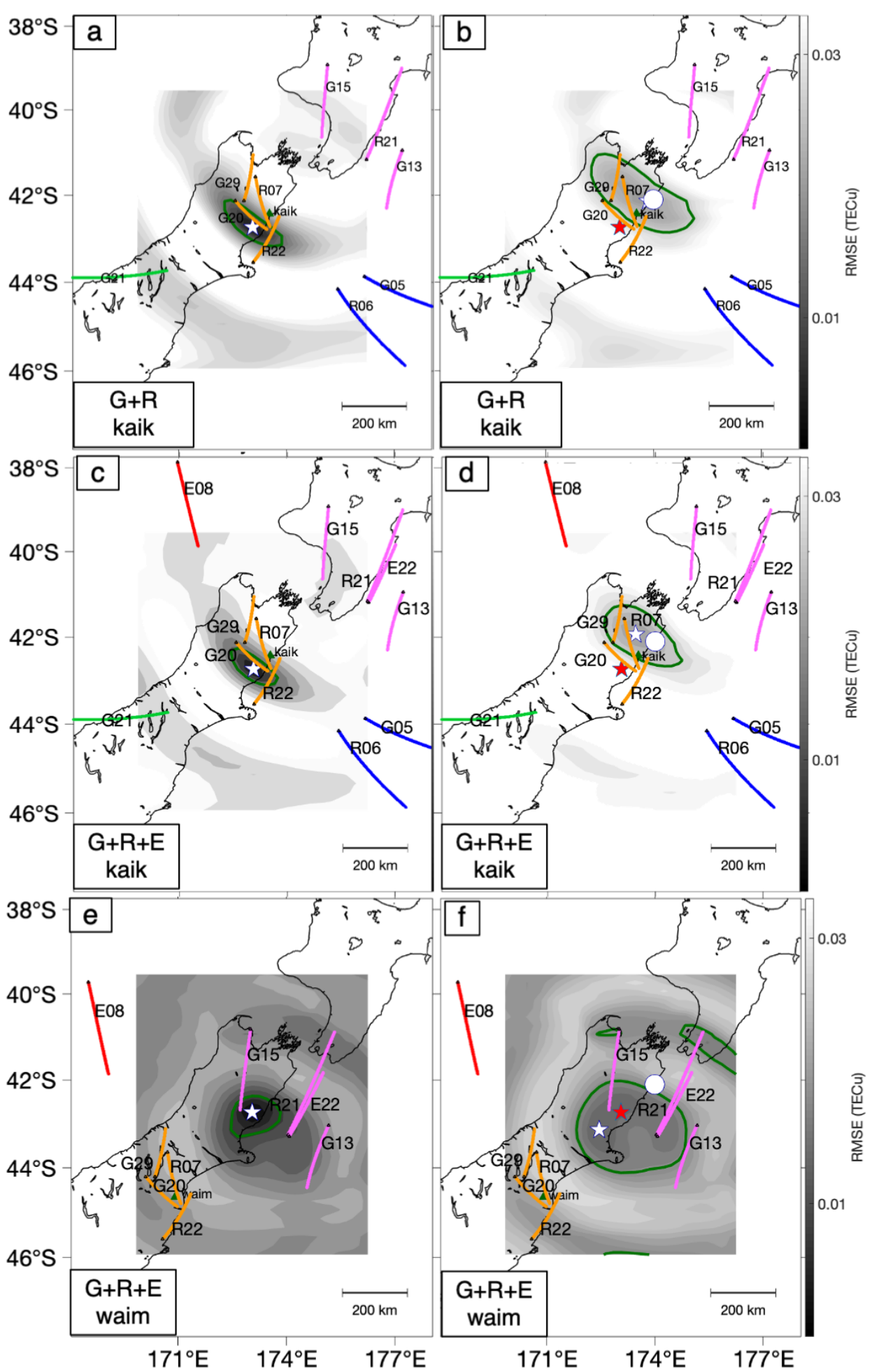

Figure 6 


\section{Appendix}

EQ. A1: Calculation of the amplitude $A$ by thorough normalization by synthetic time series amplitude leads to

$A=\frac{\max \left(\sqrt{d_{o}{ }^{2}+H\left(d_{o}\right)^{2}}\right)}{\max \left(\sqrt{{d_{s}{ }^{2}+H\left(d_{s}\right)^{2}}^{2}},\right.}$

where $d_{o}$ is the observed time series and $d_{s}$ is the synthetic time series. $\mathrm{H}$ is the Hilbert transform of the signal. In this way, given that we cannot fully account for the 3D geometric effects of components like the LOS integration, we normalize the observed data by the synthetic data to account for geometric amplitude affects prior to applying the grid-search method. This approach helps to remove the imprint of the IPP geometry and provide more realistic relative amplitudes of the acoustic wave prior to stacking during the grid search. 
Table A1: Van best fit parameters (per satellite).

$\begin{array}{cccccc} & \text { G21 } & \text { G29 } & \text { G30 } & \text { R02 } & \text { R17 } \\ \text { SIRN } & 0.26 & 0.97 & 0.22 & 0.30 & 0.49 \\ \text { MURA } & 0.69 & 0.75 & 0.51 & 0.75 & 0.67\end{array}$

Table A2: Kaikoura best fit parameters (per satellite).

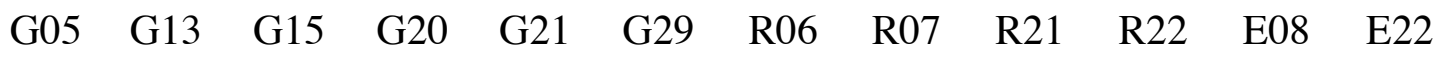

$\begin{array}{lllllllllllll}\text { KAIK } & 0.37 & 1.43 & 2.03 & 1.38 & 0.75 & 2.36 & 3.25 & 2.08 & 1.73 & 1.64 & 2.00 & 1.77\end{array}$

$\begin{array}{lllllllllllll}\text { WAIM / } & 1.05 & 0.62 & 1.70 & / & 0.97 / & / & 3.29 & 1.49 & 2.89 & 1.40 & 0.88\end{array}$ 


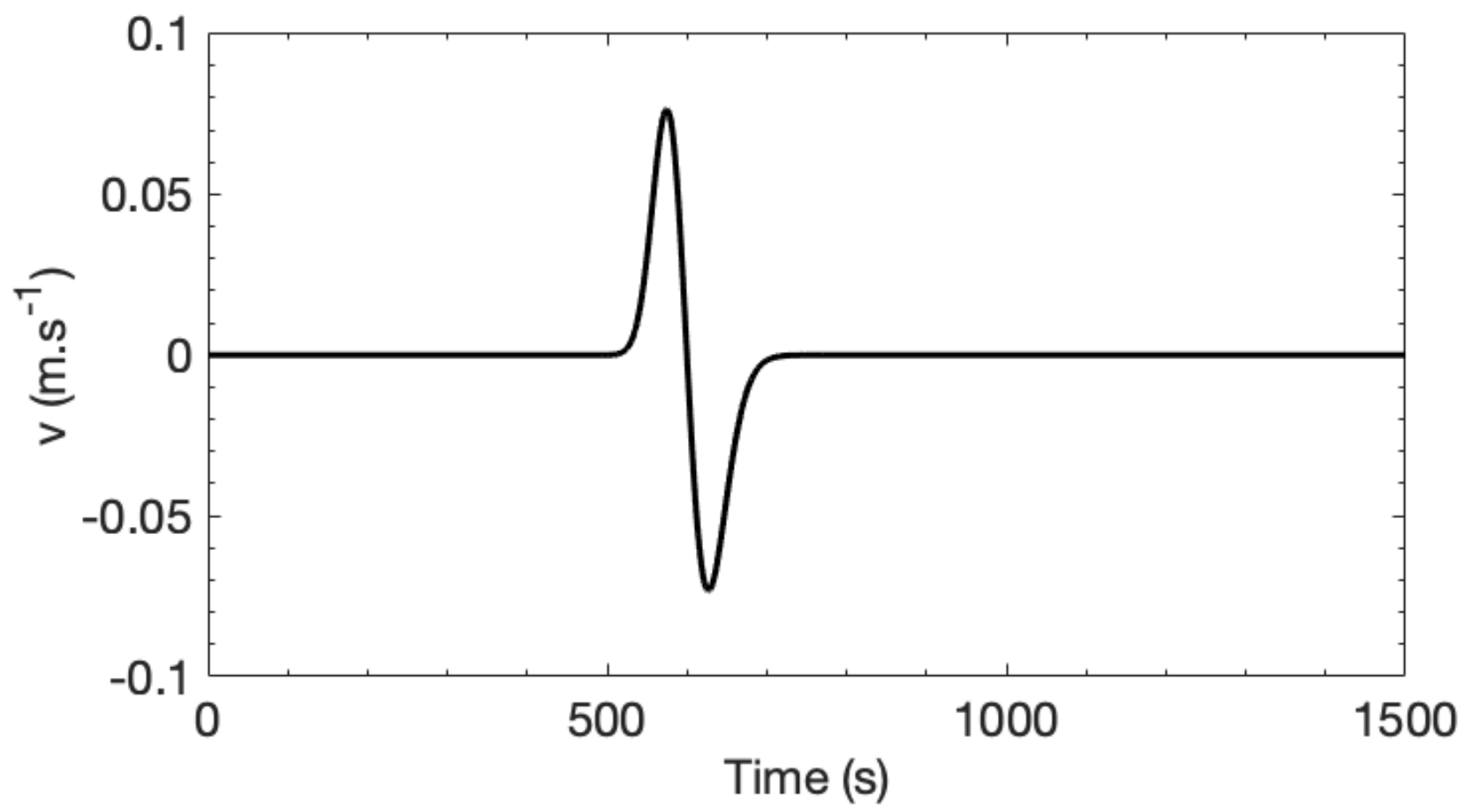

Fig. A1: N-shape wave visualization. This function represents the speed of the atmospheric particle 500 s after initiation. Here $A_{0}=1$ and $b=0.06$. 

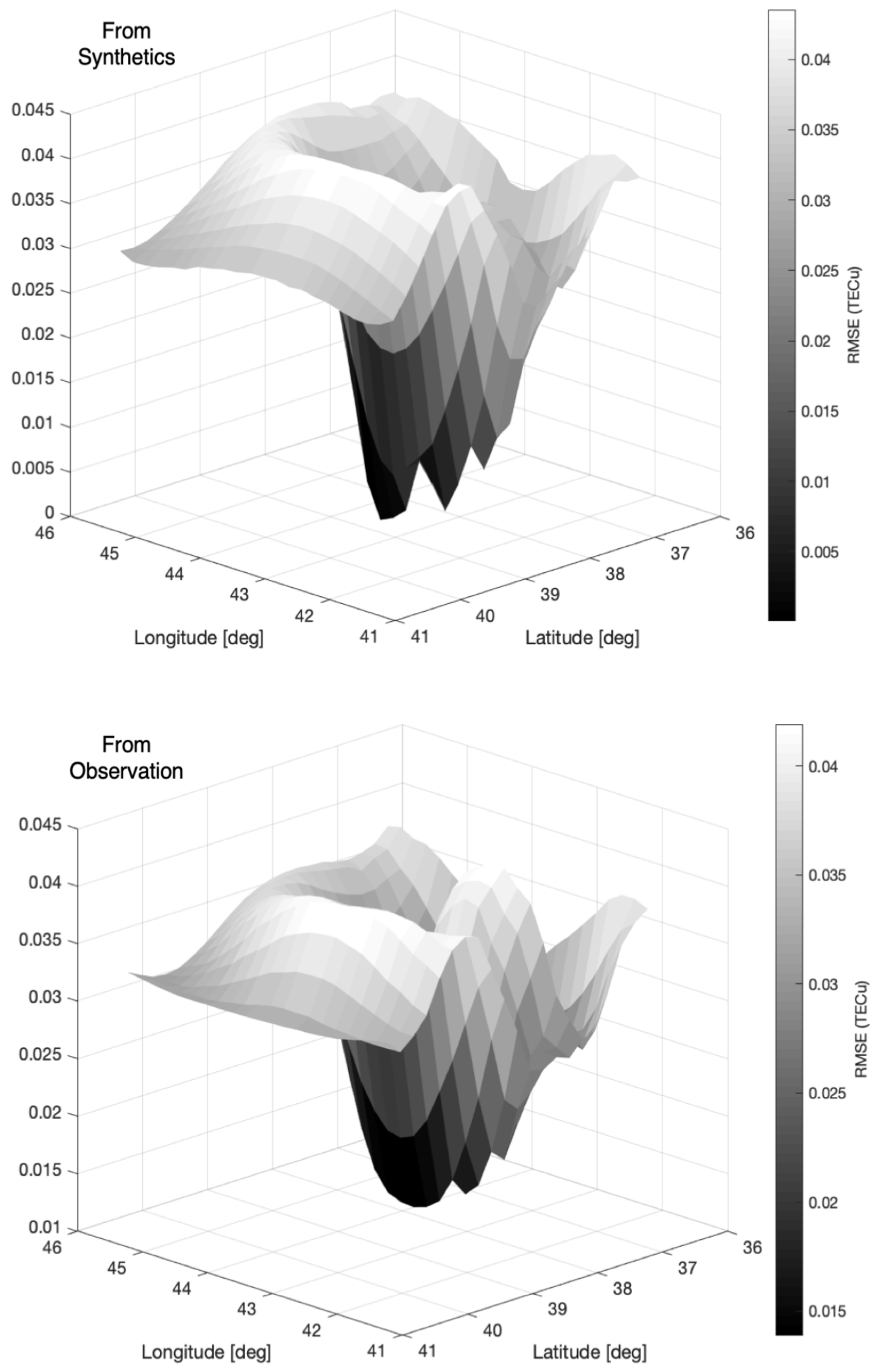

Fig. A2: RMSE variations in 3-D for trial source localization of the synthetics (top) and the field data (bottom) for SIRN during the Van earthquake. 


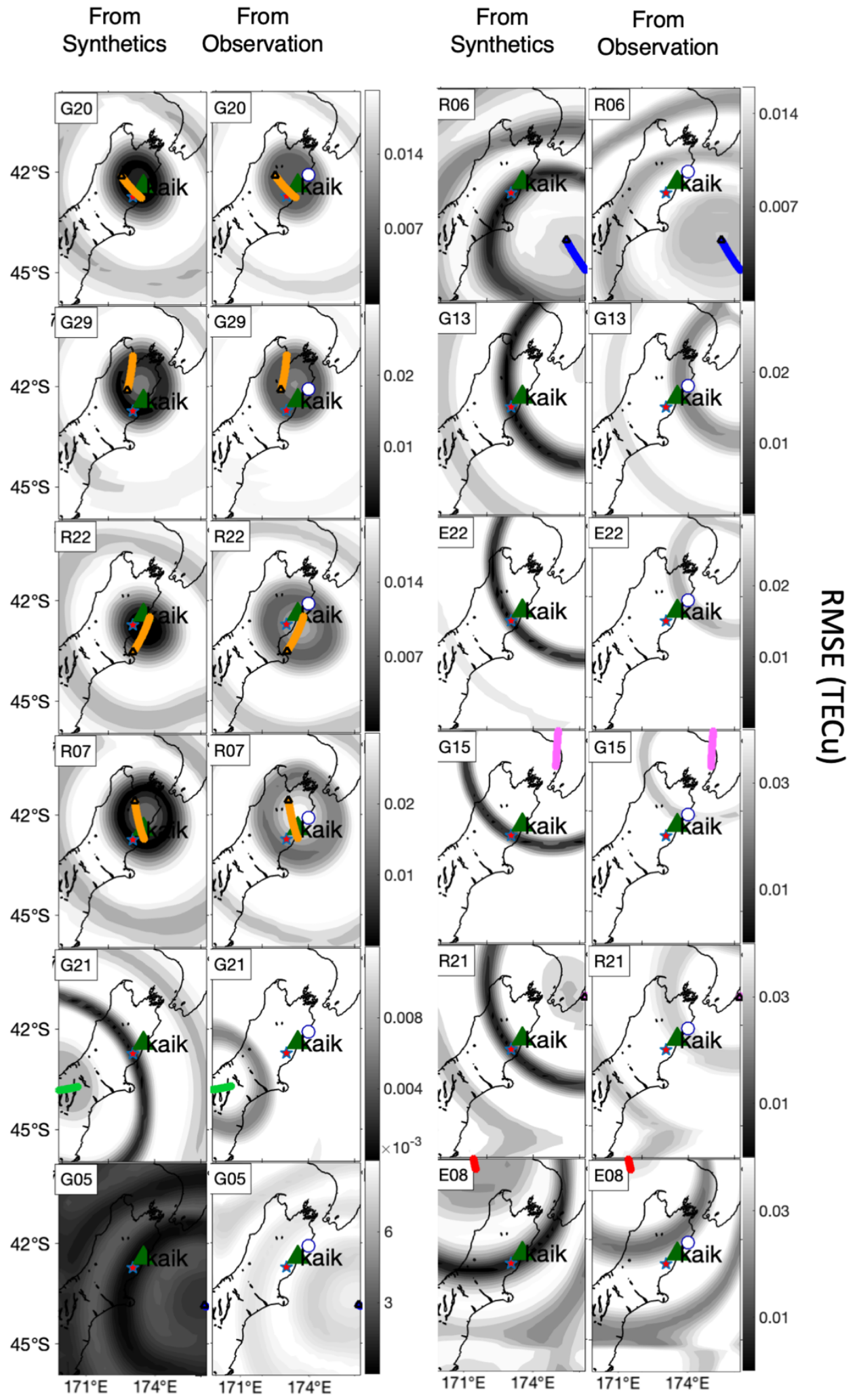

Fig. A3: Same as Fig. 5 for the twelve individual satellites. 

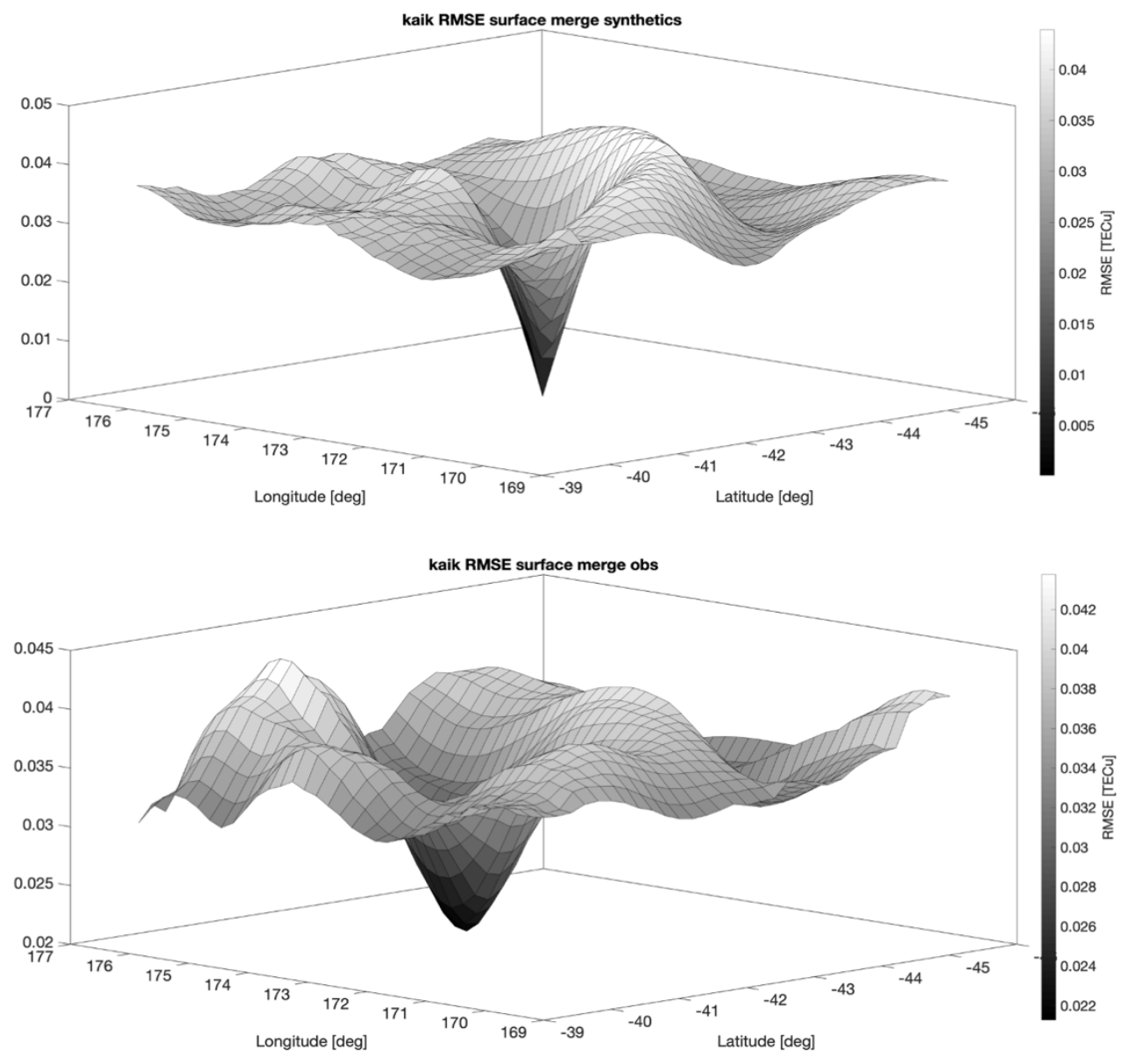

Fig. A4: RMSE variation in 3-D for trial source localization of the synthetics (top) and the field data (bottom) for KAIK during the Kaikoura earthquake. 


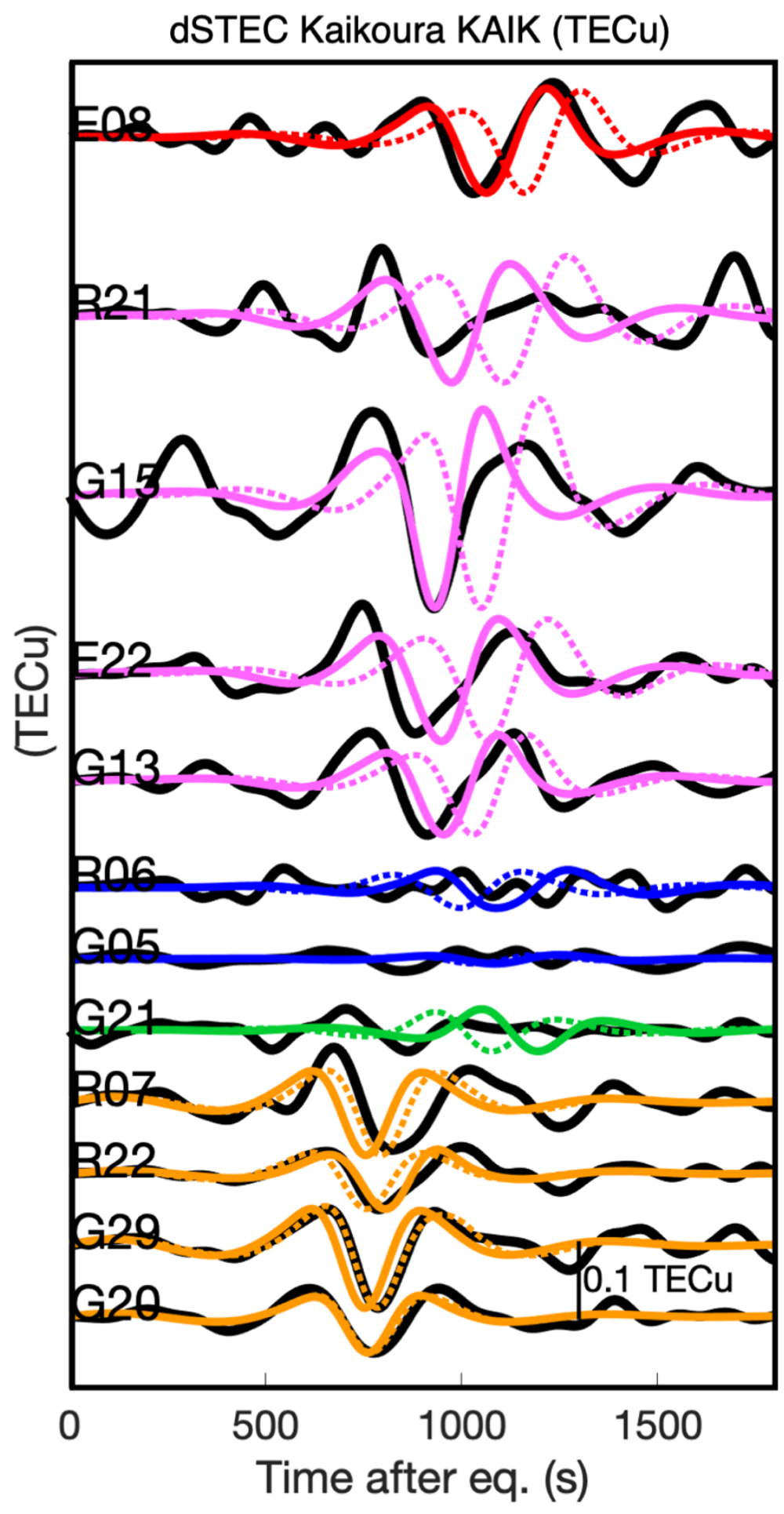

Fig. A5: Best-fit CID time series result for GNSS stations KAIK for the Kaikoura earthquake. Observed (black) and synthetics (colored) from the best-fit trial source (solid line) and from the USGS epicenter (dotted line). Note that the amplitude scaling factor is adjusted to fit the maximum of energy of the observed time series. 

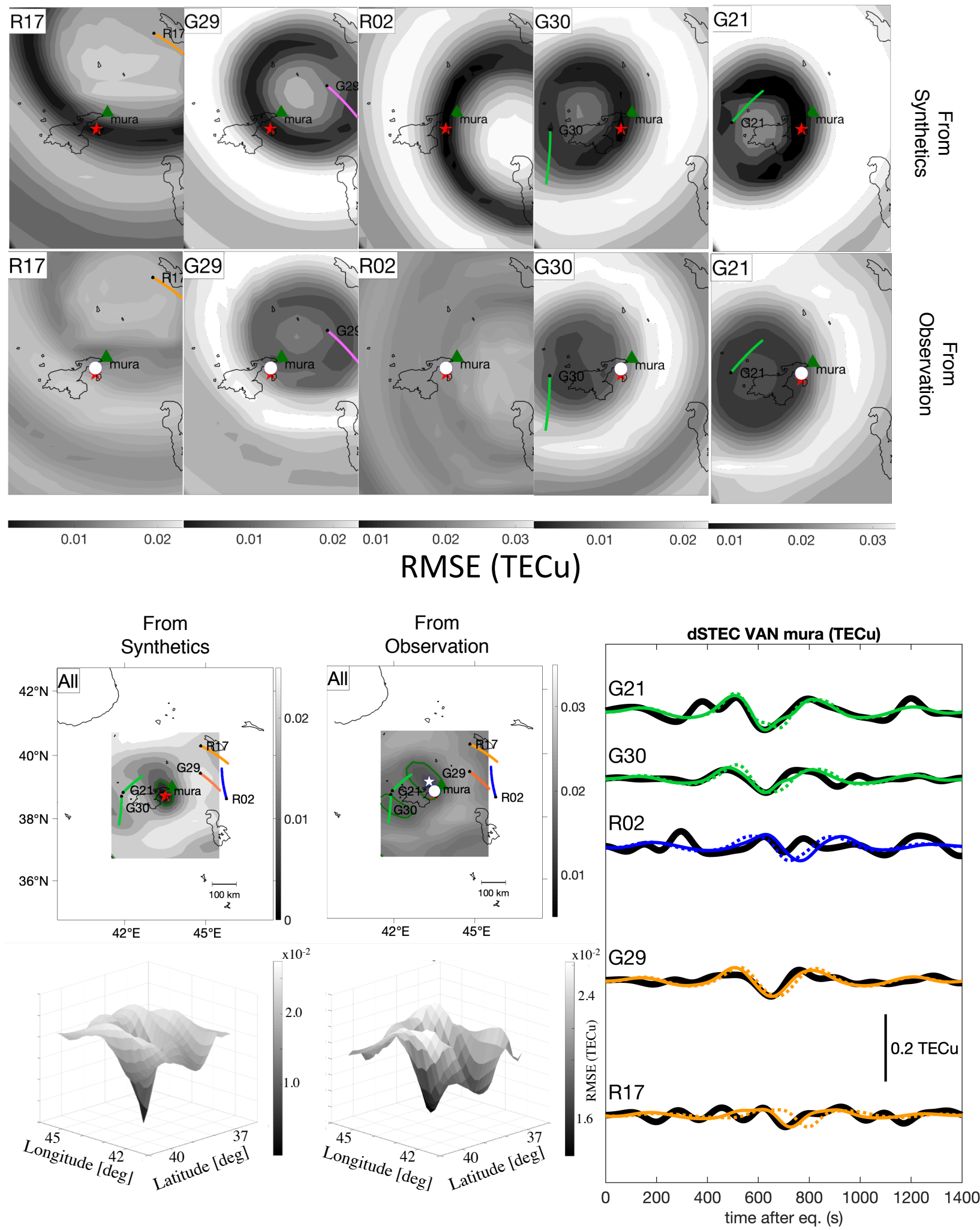

Fig. A6: Complete Van earthquake study for GNSS station MURA (GPS+GLONASS). The retrieved acoustic source is located at $39.12^{\circ} \mathrm{N}, 43.31^{\circ} \mathrm{E}$. See Fig. 2, 3, and 4 for detailed information. 

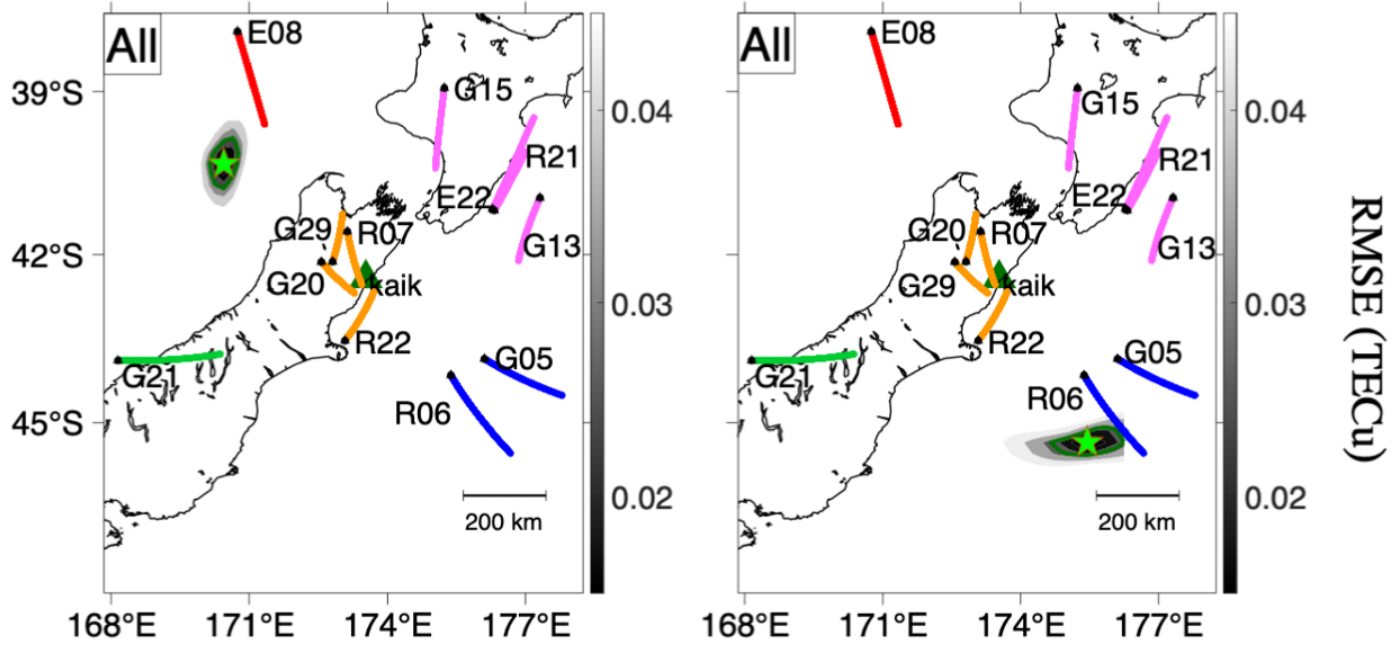

Fig. A7: Synthetic ionospheric localization of 2016 Mw 7.8 Kaikoura earthquake acoustic source using KAIK GNSS station. Total RMSE grid search maps (TECu) using KAIK station for the twelve visible satellites. Left panel: acoustic source northwest of the epicenter. Right panel: acoustic source southeast of the epicenter. 

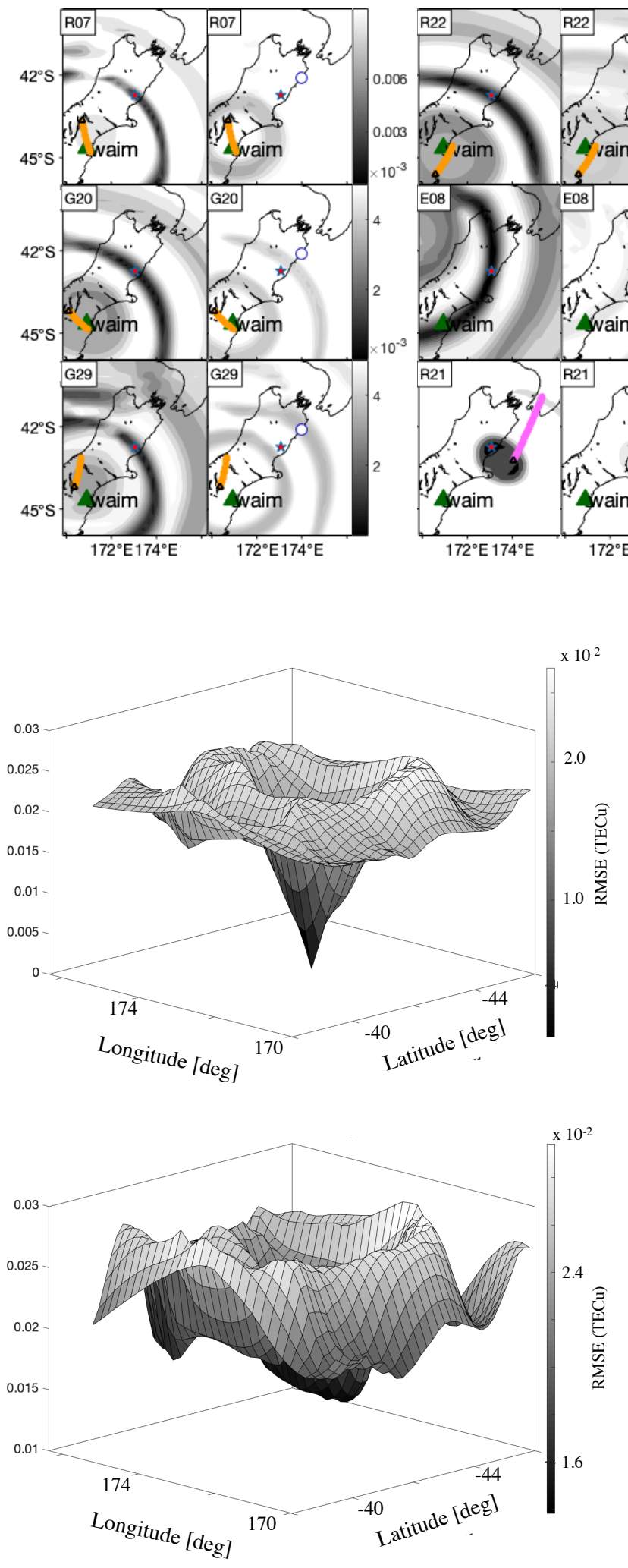
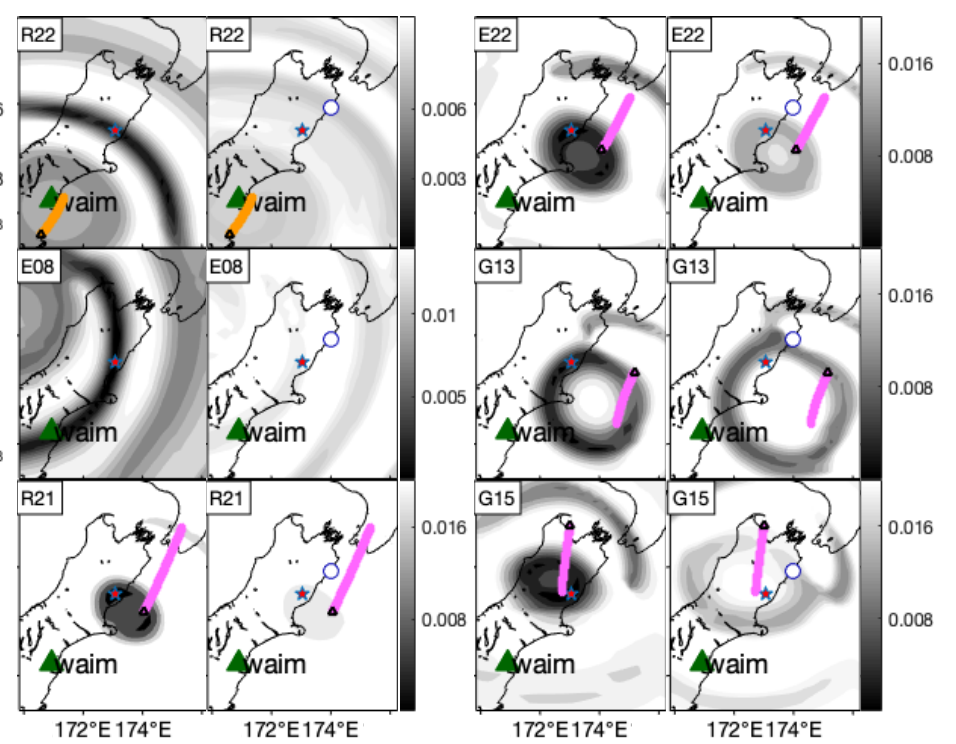

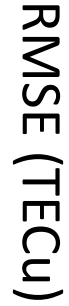

dSTEC Kaikoura WAIM (TECu)

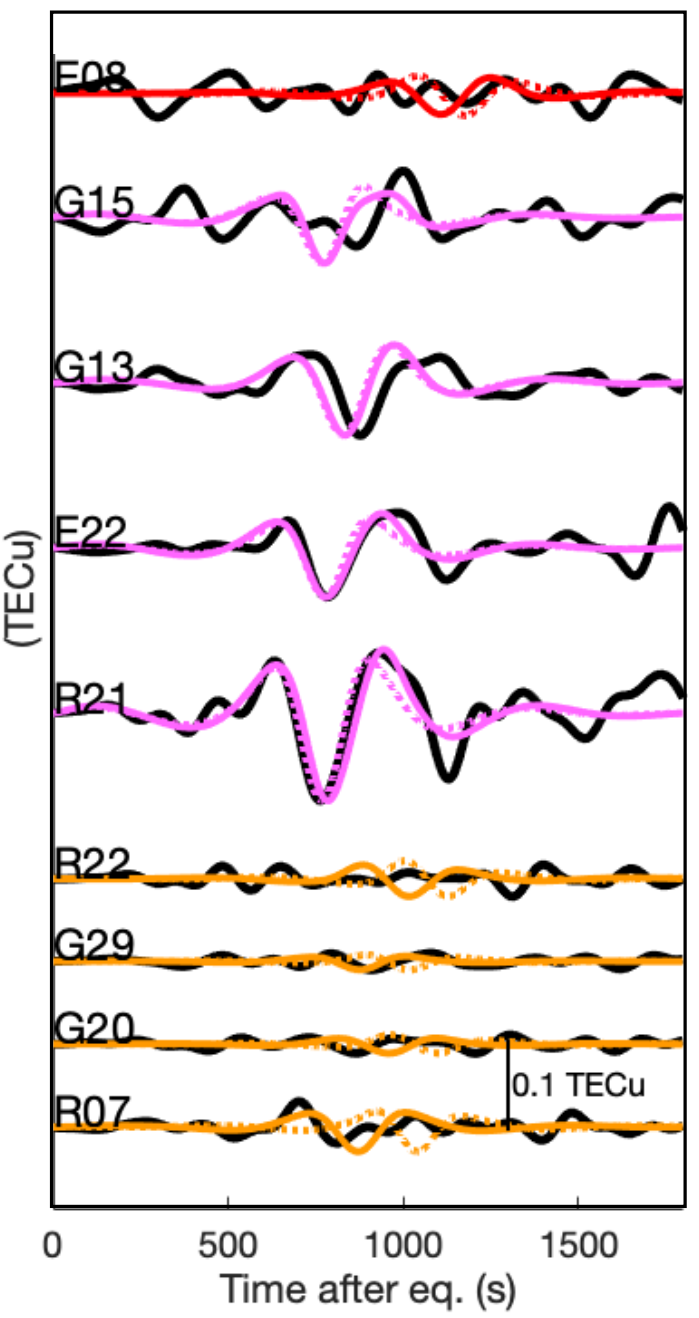

Fig. A8: Kaikoura earthquake study for GNSS station WAIM (GPS+GLONASS+GALILEO). Top panel: individual satellite inversion maps. Bottom left panel: 3D RMSE variation of figure 6.e and 6.f and bottom right: time series observed by waim station (black curves), and synthetics (colored curves) modelled using the best-fit trial source (solid curves) and the USGS epicenter (dashed curves) 


\section{FIGURE Captions:}

Fig. 1: a) lonospheric sounding observation geometry for the $2011 \mathrm{Mw} 7.1$ Van earthquake. The red star marks the epicenter location (USGS) and the green triangle marks the SIRN GNSS station. The colored lines are the IPP tracks of the satellites for GPS (G--) and GLONASS (R--), which sound over the epicentral region (above the epicenter in orange, from south-east in blue and south west in green) starting from the earthquake initiation time (black triangle) to $1500 \mathrm{~s}$ after. The blue and green dots are trial sources at $0.2^{\circ}$ and $2^{\circ}$ East of the epicenter, respectively, b) Observed (black bold curves) and modeled (colored curves) coseismic ionospheric disturbance for different locations of the acoustic sources: the epicenter (continuous lines), $0.2^{\circ}$ (dotted lines) and $2^{\circ}$ (dashed lines) East of the epicenter. The amplitude scaling factor is the same $\left(A_{0}=1.2\right)$ in all modeled time series.

Fig. 2: Acoustic source grid-search RMSE maps using the ionospheric network formed by the SIRN GNSS station and the five GNSS satellites. (Top row) Synthetic data results. (Bottom row) Results derived from the field observations. The white disk marks the location of maximum uplift (Elliott et al. 2013). The color-coded values are the RMSE in TECu. The minimum of misfit corresponds to the darker area.

Fig. 3: Single-station ionospheric localization of $2011 \mathrm{Mw} 7.1$ Van earthquake acoustic source using the available data from five GNSS satellites recorded by station SIRN (see individual maps in Fig. 2). Results are derived either from the synthetic data (a) and the field observations (b). The white disk marks the maximum of uplift. The green contours delineate the $1 \sigma$ uncertainty. The color-coded values are the RMSE in TECu. c) Coseismic ionospheric disturbance from the best-fit acoustic source location (white star on the RMSE maps). The synthetics at the epicenter (colored solid line) and synthetics at the best-fit source location (colored dotted line) are compared to the observed time series (black).

Fig. 4: Single-station GNSS ionospheric network for the 2016 Mw 7.8 Kaikoura earthquake. a) lonospheric sounding observation geometry. The red star marks the epicenter, the green triangle the KAIK GNSS station, the colored lines are the IPP tracks of the 12 visible satellites, from the time of the rupture initiation (black triangle) to 33 minutes after. b) Observed (black) and modeled (colored) coseismic ionospheric disturbances; the model is made using an acoustic source location at the epicenter. The amplitude scaling factor is $A_{0}=1$ in all modeled time series.

Fig. 5: Acoustic source grid-search RMSE maps using the ionospheric network formed by KAIK GNSS station observing six satellites: synthetic results (left) and observed data results (right). The white disk marks the maximum of uplift location (Hamling et al. 2017). The color-coded values are the RMSE in TECu. The minimum of misfit corresponds to the darker area.

Fig. 6: Single-station ionospheric localization of the $2016 \mathrm{Mw} 7.8$ Kaikoura earthquake acoustic source using the available data from GNSS satellites (GPS+GLONASS+Galileo). The combination of 
GPS and GLONASS for KAIK station are the panels (a) and (b), the combination of GPS, GLONASS and Galileo for KAIK are the panels (c) and (d) and for station WAIM on panels (e) and (f). Results are derived either from synthetic data (panels $a, c$ and e), or from the field observations (panels $b, d$ and f). The white disk marks the maximum of uplift. The white star marks the minimum of RMSE. The green contours delineate the $1 \sigma$ uncertainty. The color-coded values are the RMSE in TECu. Tracks of used satellites are shown in color. 